\title{
What do VARs tell us about the impact of a credit supply shock?*
}

\author{
Haroon Mumtaz \\ Queen Mary College
}

\author{
Gabor Pinter \\ Bank of England
}

January 2017

\author{
Konstantinos Theodoridis \\ Bank of England
}

\begin{abstract}
In the aftermath of the recent financial crisis, a variety of structural VAR models have been proposed to identify credit supply shocks. Using a Monte-Carlo experiment, we show that the performance of these models can vary substantially with some identification schemes producing particularly misleading results. When applied to US data, the estimates from the best performing VAR models indicate, on average, that credit supply shocks that raise spreads by 10 basis points reduce GDP growth and inflation by $1 \%$ after one year. These shocks were important during the Great Recession, accounting for about half the decline in GDP growth.

JEL Classification: C15, C32, E32. Keywords: Credit supply Shocks, Proxy SVAR, Sign restrictions, identification via heteroscedasticity, DSGE models.
\end{abstract}

\section{Introduction}

A large number of recent empirical studies have focussed on identifying and estimating the impact of credit supply shocks. This issue has gained renewed prominence in the face of the Great Recession and the banking and debt crisis in the Euro-Area. For example, recent studies such as Peersman (2011), Furlanetto et al. (2014), Bijsterbosch and Falagiarda (2014), Eickmeier and $\mathrm{Ng}$ (2015) and Gambetti and Musso (2017) use sign restrictions to identify

* The views expressed in this paper are those of the authors and should not be held to represent those of the Bank of England. The authors wish to thank the editor, Jesús Fernandez-Villaverde, four anonymous referees, Tao Zha and the participants of the "Macro Applications of time series models" and "Identification in Macroeconomics" workshops organised by Bundesbank and Narodowy Bank Polski for useful comments. 
credit supply shocks. Gilchrist and Zakrajsek (2012), instead, adopt an alternative approach. They use firm level data to build an index of credit spreads and show that a component of this index (that is not related to countercyclical movements in expected defaults) can be interpreted as a proxy for credit supply. Gilchrist and Zakrajsek (2012) is related to a large body of work that has proposed different indicator variables that may provide information about credit supply, with prominent papers including Kashyap et al. (1993) and Gertler and Gilchrist (1994). Lown and Morgan (2006) uses the Federal Reserves' senior loan officers survey to build a proxy for credit supply and finds that negative shocks to this measure have a significant negative impact on GDP.

In this paper we re-examine the identification of the credit supply shock using SVARs. The aim is to investigate how SVARs perform in identifying this shock and to establish whether the estimated importance of the credit supply shock varies substantially with the identification scheme. This question is important both from a methodological and economic point of view. From the former perspective, this exercise can be seen as an attempt to shed light on the relative performance of the SVAR models used in the papers cited above. More importantly, our work attempts to estimate the impact of this shock while accounting for the uncertainty associated with identification. In other words, this paper tries to provide general results on the role played by this shock in driving recent fluctuations in economic activity-a question that is vital for policy-makers.

With this aim in mind, the paper considers a Monte-Carlo experiment where the data is generated from DSGE models featuring credit supply. The artificial data is used to estimate five types of structural VAR models with the objective of identifying credit supply shocks. The first SVAR model uses DSGE based sign restrictions to identify the credit supply shock à la Gambetti and Musso (2017). We also consider an augmented sign restriction scheme where restrictions on the forecast error variance (FEV) decomposition are also added in addition to the sign restrictions. The third SVAR treats the simulated credit shock as a proxy variable and adds it to the VAR as an endogenous variable, and mimics the recursive approach to identification adopted in Lown and Morgan (2006) and Gilchrist and Zakrajsek (2012), for example. In addition, we estimate a proxy SVAR model (as proposed in Stock and Watson (2008) and Mertens and Ravn (2014)) where the simulated proxy is used as an instrument to estimate the credit supply shock. The final SVAR model is based on the data driven approach based on Rigobon (2003) and Lanne et al. (2010), and identifies the credit supply shock via heteroscedasticity. The results of this Monte-Carlo experiment suggest that the SVAR with sign and FEV restrictions and the proxy SVAR model deliver the best performance producing impulse responses that match those from the DSGE model. The scheme based on heteroscedasticity works well under certain conditions. In contrast, the recursive SVAR is sensitive to ordering and measurement error and can produce estimates that are very misleading.

We then estimate these SVAR models using US data. While there is some dispersion of the results across models, the SVARs that perform well in the Monte-Carlo experiment lead to fairly similar empirical results. On average across models, a credit supply shock that leads 
to a rise in the credit spread by 10 basis points, is estimated to reduce annualised quarterly GDP growth by $1 \%$ after one year on a cumulative basis. The cumulative impact of this shock on annual inflation at this horizon is similar with this variable declining by $1 \%$. The credit supply shock explains about $13 \%$ of the FEV of GDP and $18 \%$ of the FEV of inflation at the one year horizon. We find strong evidence that this shock made a large contribution to the decline in GDP growth and inflation over the Great Recession. The estimates suggest that the decline in GDP growth in 2009 would have been reduced by $50 \%$ if the negative credit supply shock at that time had been absent. These results, therefore, re-enforce the message of recent DSGE papers such as Liu et al. (2013) and Christiano et al. (2014) amongst others that financial frictions and shocks are an important source of macroeconomic fluctuations.

The paper is organised as follows. Section 2 introduces the various approaches to estimating the impact of credit supply shocks via SVARs. The Monte-Carlo experiment is presented in section 3, while section 4 presents the empirical results for the US. Section 5 concludes.

\section{The SVAR approach to estimating the impact of credit supply shocks}

\subsection{Sign Restrictions}

As mentioned, above a number of recent papers have used sign restrictions in an attempt to identify credit supply shocks. The starting point of our analysis is a reduced-form VAR written as:

$$
Y_{t}=c+\sum_{j=1}^{P} B_{j} Y_{t-p}+A_{0} \varepsilon_{t}
$$

where $Y_{t}$ is a vector of endogenous variables. The structural shocks $\varepsilon_{t}$ are related to the VAR residuals $u_{t}$ via the relation $A_{0} \varepsilon_{t}=u_{t}$ where $A_{0}$ is a matrix such that $V A R\left(u_{t}\right)=\Omega=A_{0} A_{0}^{\prime}$.

Studies such as Gambetti and Musso (2017) include five variables in the VAR model: Real GDP, CPI, volume of loans, a lending rate and a short-term interest rate. The credit supply shock $\varepsilon_{t}^{c}$ is identified via the assumption that a contractionary shock leads to a decrease in real GDP and the volume of loans and an increase in the lending rate. A similar scheme is implemented for the UK by Barnett and Thomas (2014). Peersman (2011) uses a more general sign restrictions scheme to identify a lending multiplier shock, where data on lending net of the monetary base is utilised to distinguish this shock from a monetary easing.

As described in Rubio-Ramirez et al. (2010), the algorithm to find $A_{0}$ proceeds by first calculating $\tilde{A}_{0}$ an arbitrary matrix square root of $\Omega$. Then a candidate $A_{0}$ is found by multiplying $\tilde{A}_{0}$ with a rotation matrix and checking if the impulse responses using this candidate structural impact matrix satisfy the sign restrictions. Note that this algorithm delivers a set of $A_{0}$ matrices and impulse responses that are admissable under the identification scheme. The recent literature on this SVAR methodology has focussed on this latter aspect. Baumeister and Hamilton (2015) show that even asymptotically, the posterior of $A_{0}$ is confined to 
the set of values that orthogonalises the true variance covariance matrix and is proportional to the prior distribution. Baumeister and Hamilton (2015) suggest that researchers should explicitly specify prior beliefs about $A_{0}$ and acknowledge their influence on the posterior estimates. Giacomini and Kitagawa (2014) propose the use of multiple priors on the rotation matrices in order to conduct inference that is robust to the choice of priors. Arias et al. (2014) highlight the importance of using priors that are agnostic, i.e. equivalent over parameters such as $A_{0}$ and its rotations that have the same reduced form representation.

Given that the set of admissable $A_{0}$ matrices can be fairly wide, we also consider a scheme that augments the sign restrictions with the requirement that the identified shock also maximises the FEV contribution to the quantity of credit up to a horizon of 40 quarters (see Uhlig (2004)). This augmented scheme is similar in spirit to the 'plausibility restriction' approach adopted in Kilian and Murphy (2012). In our application we rule out $A_{0}$ matrices that deliver credit supply shocks that contribute little to fluctuations in the quantity of credit. From an economic point of view, this additional restriction is motivated by the observation that the monetary authority can use its policy instruments to mitigate the impact of credit demand shocks. In contrast, credit technology shocks that disrupt supply are harder to deal with and are likely to affect credit quantity over a longer period of time.

\subsection{Proxy Variables in a recursive SVAR}

The VAR analysis in Lown and Morgan (2006), Gilchrist and Zakrajsek (2012) and Bassett et al. (2014) relies on building a proxy for credit supply $\hat{\varepsilon}_{t}^{c}$ and adding it to the VAR model as an endogenous variable. For example, Lown and Morgan (2006) use net percentage tightening of credit standards from the US senior loan officers' survey as a proxy and show that shocks to this variable result in a decline in output and the quantity of lending. Bassett et al. (2014) refine this measure further by removing the component associated with macroeconomic factors influencing loan demand. Increases in their residual measure are associated with a fall in output and widening of credit spreads. Gilchrist and Zakrajsek (2012) use a firm level dataset on corporate bond prices to build an aggregate spread index. They then decompose this aggregate corporate bond spread into a component explained by firm specific expected default and firm specific bond characteristics and a residual component-i.e. the excess bond premium. The authors argue that this residual component represents: '(the) average price of bearing exposure to U.S. corporate credit risk, above and beyond the compensation for expected defaults'. Gilchrist and Zakrajsek $(\overline{2012})$ interpret the excess bond premium as a proxy for credit supply and show that it is highly correlated with measures of supply derived from the senior loan officers survey. When added to a VAR model (positive) shocks to the excess bond premium lead to a significant reduction in GDP growth, consumption growth and investment in the US.

Given that $\hat{\varepsilon}_{t}^{c}$ is a proxy for true underlying value of the credit supply shock, it is reasonable to assume a degree of measurement error. For example, the relationship between the constructed measure of credit supply and its underlying value may be defined as $\hat{\varepsilon}_{t}^{c}=\varepsilon_{t}^{c}+\sigma_{v} v_{t}$ where $v_{t}$ is standard normal. It is easy to see that the presence of measurement error would 
bias the estimate of the structural shock of interest. In addition, it is well known that OLS estimates of the VAR coefficients would suffer from attenuation bias due to the correlation between the RHS variables and the residuals introduced by the measurement error.

\subsection{Proxy SVAR}

Stock and Watson (2008) and Mertens and Ravn (2014) have recently proposed a structural VAR approach that uses proxy variables as instruments rather than additional endogenous variables. The underlying VAR model is given by the following equation:

$$
\tilde{Y}_{t}=c+\sum_{j=1}^{P} B_{j} \tilde{Y}_{t-p}+\tilde{A}_{0} \tilde{\varepsilon}_{t}
$$

The vector of endogenous variables $\tilde{Y}_{t}$ does not contain the constructed measure of credit supply directly but, instead, this is used as an instrument to estimate the structural shock of interest, i.e. $\varepsilon_{t}^{c}$. Denoting the remaining shocks by $\tilde{\varepsilon}_{t}^{\bullet}$, this approach requires the proxy for credit supply $\hat{\varepsilon}_{t}^{c}$ to satisfy the following conditions

$$
\begin{aligned}
E\left(\hat{\varepsilon}_{t}^{c}, \varepsilon_{t}^{c}\right) & =\alpha \neq 0 \\
E\left(\hat{\varepsilon}_{t}^{c}, \tilde{\varepsilon}_{t}^{\bullet}\right) & =0 \\
\operatorname{VAR}\left(\tilde{\varepsilon}_{t}\right) & =D=\operatorname{diag}\left(\sigma_{\varepsilon_{1 t}}, \ldots \sigma_{\varepsilon_{N t}}\right)
\end{aligned}
$$

The first expression in equation 3 states that the instrument $\hat{\varepsilon}_{t}^{c}$ is correlated with the structural shock to be estimated, while the second expression rules out any correlation between $\hat{\varepsilon}_{t}^{c}$ and the remaining structural shocks and establishes exogeneity of the instrument. The final condition ensures that the shocks are contemporaneously uncorrelated. As shown in Stock and Watson (2008), Mertens and Ravn (2013) and Mertens and Ravn (2014), these conditions along with the requirement that the structural shocks $\tilde{\varepsilon}_{t}$ are contemporaneously uncorrelated can be used to derive a GMM estimator for the column of $\tilde{A}_{0}$ that corresponds to $\hat{\varepsilon}_{t}^{c}$. Letting $\tilde{A}_{0}=\left[\tilde{A}_{0,1} \ldots . \tilde{A}_{0, N}\right]$ and $\tilde{A}_{0} \tilde{\varepsilon}_{t}=u_{t}$ where $V A R\left(u_{t}\right)=\Omega$. Then Stock and Watson (2008) show that that $\varepsilon_{1 t}$ can be estimated via a regression of $\hat{\varepsilon}_{t}^{c}$ on $u_{t}$. Note that $E\left(u_{t} \hat{\varepsilon}_{t}^{c}\right)=E\left(\tilde{A}_{0} \varepsilon_{t} \hat{\varepsilon}_{t}^{c}\right)=\left[\tilde{A}_{0,1} \ldots \tilde{A}_{0, N}\right]\left[\begin{array}{c}E\left(\varepsilon_{1 t} \hat{\varepsilon}_{t}^{c}\right) \\ \cdot \\ \cdot \\ E\left(\varepsilon_{N t} \hat{\varepsilon}_{t}^{c}\right)\end{array}\right]=\tilde{A}_{0,1} \alpha$. Let $\Pi$ denote the coefficient on $u_{t}$. Then the fitted value $\Pi u_{t}$ equals the structural shock of interest up to sign and scale:

$$
\begin{aligned}
\Pi u_{t}= & E\left(\hat{\varepsilon}_{t}^{c} u_{t}^{\prime}\right) \Omega^{-1} u_{t} \\
= & \alpha \tilde{A}_{0,1}^{\prime}\left(\tilde{A}_{0} D \tilde{A}_{0}^{\prime}\right)^{-1} u_{t} \\
& \alpha\left(\tilde{A}_{0,1}^{\prime} \tilde{A}_{0}^{-1^{\prime}}\right) D^{-1}\left(\tilde{A}_{0}^{-1} u_{t}\right) \\
= & \frac{\alpha \varepsilon_{1 t}}{D_{11}}
\end{aligned}
$$


where going from the third to the final line uses the fact that $\left(\tilde{A}_{0,1}^{\prime} \tilde{A}_{0}^{-1^{\prime}}\right)=[1,0, \ldots 0]$ and $\tilde{A}_{0}^{-1} u_{t}=\varepsilon_{t}$. Note that equation 3 imposes less stringent conditions on the quality of $\hat{\varepsilon}_{t}^{c}$ than those required for unbiased estimation when the proxy variable is added directly to the VAR model. In particular, the only requirements are that $\hat{\varepsilon}_{t}^{c}$ is correlated with the shock of interest and uncorrelated with other shocks. These conditions can be satisfied even if $\hat{\varepsilon}_{t}^{c}$ is measured with error.

\subsection{Identification through heteroscedasticity}

Building on Rigobon (2003), Lanne et al. (2010) describe how heteroscedasticity in the structural shocks can be used to estimate the contemporaneous impact matrix in equation 1. In particular, Lanne et al. (2010) consider the following parameterisation for the variance of $u_{t}$.

$$
\operatorname{var}\left(u_{t}\right)=\Omega_{s_{t}}
$$

where $s_{t}=1,2, . . M$ follows a Markov process with transition probabilities $p_{i j}=\operatorname{Pr}\left(s_{t}=j \backslash s_{t-1}=i\right)$. The covariance matrix $\Omega_{s_{t}}$ is defined as:

$$
\begin{aligned}
\Omega_{1} & =B B^{\prime} \\
\Omega_{i} & =B \Lambda_{i} B^{\prime}
\end{aligned}
$$

where $i=2, \ldots, M$ and $\Lambda_{i}$ is a diagonal matrix that represents the volatility of the structural shocks relative to the first regime. Lanne et al. (2010) show that expression 5 provides enough equations to estimate the unknown elements of $B$ uniquely (up to sign changes and column permutations) provided that there exists a state where the diagonal elements of $\Lambda$ are distinct. There are two noteworthy features of this set-up. First, it assumes that the contemporaneous and lagged impact of the shocks is time-invariant and temporal changes are fully captured by $\Lambda_{i}$. Second, the estimate of the contemporaneous impact matrix from this procedure is purely statistical and the impulse responses have to be given an economic interpretation ex-post.

\section{A Monte-Carlo experiment}

In order to assess the performance of these identification schemes, we simulate data from DSGE models featuring credit. The SVAR models are estimated using this artificial data and the estimated impulse responses to credit supply shocks are compared with those implied by the models

\subsection{The design of the experiment}

We consider three recently proposed DSGE models as three alternative DGPs. We use the monetary model developed by Gertler and Karadi (2011) in our first experiment. In addition, 
we employ the estimated DSGE model from Christiano et al. (2014) as a second DGP. Finally, we use the DSGE model developed by Curdia and Woodford (2010). These three models incorporate different financial frictions and stochastic shocks. The Gertler and Karadi (2011) model considers a moral hazard friction and the credit shock alters the assets side of financial intermediary's balance sheet. In contrast, the Christiano et al. (2014) model is subject to a costly verification friction and the shock increases the information asymmetry between borrowers and lenders. In the Curdia and Woodford (2010) model, households can only save or borrow through financial intermediaries, where these entities are unable to distinguish between borrowers who default and those who repay loans. The three model considered in this section, therefore, cover a wide spectrum of credit frictions and shocks and reduce the probability that the simulation results are model specific.

In the Gertler and Karadi (2011) model, the economy is populated by five agents: households, financial intermediaries, intermediate goods producers, retailers, and capital goods producers. By assumption, households are limited to saving via the banking system owing to prohibitively large costs associated with direct intermediation to firms. Intermediate goods producers, in turn, are reliant on bank loans to finance the physical capital, which they purchase from capital producers, who are subject to investment adjustment costs. Intermediate goods producers combine capital with labour, provided by households, to produce wholesale goods, which are bought and repackaged by monopolistically competitive retailers. Retailers are subject to Calvo-type pricing and backward indexation rules. All profits in the economy are ultimately repaid to households.

The representative household consists of "workers" and "bankers". Workers supply labour and return their wages to the household. Bankers manage financial intermediaries and return non-negative dividends to the household. The fraction of the household who save do not directly provide funds to producers, but supply savings to banks other than the ones they own. Savings take the form of riskless short term deposits. Household deposits together with banker's own net worth form banks' liabilities, which finances the purchase of financial claims on producers.

The heart of the model is a moral hazard problem between depositors and banks. At the beginning of each period the banker can choose to divert a fraction $\theta$ of available funds from the project and transfer them back to the household, in which case depositors would recover the remaining $1-\theta$ fraction of assets. In order for depositors to continue to supply funds, the bank's franchise value must be sufficiently large to satisfy the incentive constraint. The bank's optimality condition pins down the optimal leverage ratio, at which point the banker's incentive to divert assets is exactly offset by the cost of bankruptcy. To model credit shocks, we consider the capital quality shock, originally studied by Gertler and Karadi (2011). This shock destroys a fraction of the productive capital stock, which, since claims on capital are held on the balance sheets of banks, imposes losses directly on financial intermediaries leading to a fall in credit supply and a rise in spreads. Given that the shock has a direct impact on capital, it has both demand and supply effects on credit. Therefore we experiment with additional candidates that can perhaps more tightly be interpreted as credit supply shocks. 
We use shocks to the incentive constraint of the financial intermediary, which mimics the shock used by Jermann and Quadrini (2012) in a model with financial frictions on the firm's side. Third, we experiment with shocks to bank net worth which has also been used by recent papers (Gerali et al. (2010), Christiano et al. (2014)) as a proxy for credit supply shocks. As shown in the technical appendix, each one of the three credit supply shocks imply the same sign restrictions, and these signs are all distinguishable from those associated with the other four structural shocks.

We follow Gertler and Karadi $(\overline{2011})$ in setting both the conventional parameters and the parameters specific to the credit friction of the model. The standard deviation of the five shocks is set such that each of them explain $20 \%$ of the analytical FEV of output. Note that a switching version of this model is also simulated in order to evaluate the SVAR with heteroscedasticity. In this case, we allow the volatility of shocks to switch between two regimes, where the second regime is assumed to be the high volatility state. The shock volatilties in the second regime are chosen such that they are distinct thus ensuring that the identification conditions for the SVAR with heteroscedasticity are met in the generated data. For this simulation, in the benchmark case we assume that the variance of the credit supply shock in the second regime is five times larger relative to the first regime and that this shock is the most volatile compared to the other shocks.

The Christiano et al. (2014) model features risk-neutral entrepreneurs who borrow from perfectly competitive mutual funds who take deposits from households. Entrepreneurs use the borrowed funds to buy raw capital and convert it into effective capital services. Effective capital is subject to an idiosyncratic productivity shock which is independent across time and across entrepreneurs. After the realisation of the shock, entrepreneurs rent out capital services to the imperfectly competitive producers of intermediate goods. At the end of the period, some entrepreneurs' capital investment yields returns that are not high enough to cover their debt repayment, thereby leading to bankruptcy.

In case of bankruptcy, the mutual fund monitors the entrepreneur and seizes all its assets. Monitoring is costly, which creates an inefficiency. As in Gale and Hellwig (1985), the financing relationship between the entrepreneur and the mutual fund takes the form of a standard debt contract. In order for the mutual fund sector to break even, the interest rate on lending increases above the deposit rate (thereby raising spreads) when the probability of bankruptcy increases in the face of adverse macroeconomic shocks. However, increased lending rates (ensuring that mutual funds do not make losses on average) increase the borrowing costs of all entrepreneurs, thereby hurting those entrepreneurs that do not go bankrupt. In this sense, increased borrowing costs act like a tax on aggregate investment. A major source of aggregate fluctuations comes from disturbances to the distribution of idiosyncratic productivity shocks, which CMR refers to as risk shocks.

The rest of the model is relatively standard, featuring habits in consumption, competitive final goods producers, monopolistically competitive intermediate goods producers, price and wage stickiness in the spirit of Calvo (1983), investment adjustment costs, variable capital utilisation and a Taylor-type monetary policy rule. For our simulation purposes, we use 5 
aggregate shock processes: a government spending shock, a non-stationary TFP shocks, an investment specific shock, a monetary policy shock and the credit (risk) shock, which takes a centre stage in CMR because it implies countercyclical credit spreads and procyclical investment, consumption, employment, inflation, stock market, and credit, which corresponds well to the analogous features of US business cycle data as argued by the authors. The value of the parameters is set equal to those obtained via estimation using US data. Note that, as in the case of the Gertler and Karadi (2011) DGP, we also consider a heteroscedastic version of the model where the variance of the credit supply shock is five times higher than the estimated value in the volatile regime.

The Curdia and Woodford (2010) model is more stylised than Gertler and Karadi (2011) in that it abstracts from the distinction between the household and firm sectors, and instead treats all private expenditure as the expenditure of household firms. Also, the model abstracts from investment spending and all private expenditure is nondurable consumer expenditure (yielding immediate utility at a diminishing marginal rate). The key modelling assumption is the coexistence of two types of households: a borrower and a saver. Each period, with probability $1-\delta$ a new type for the household is drawn, otherwise, the household remains the same as in the previous period. When a type is drawn, it is a borrower with probability $\pi_{b}$ and saver with probability $\pi_{s}$. The two types differ in their marginal utilities of consumption. This implies that a change in household type changes the household's relative impatience to consume.

As in Gertler and Karadi (2011), financial intermediaries take centre stage in Curdia and Woodford (2010) as well. They assume that households are able to spend an amount different from their current income only by depositing funds with or borrowing from financial intermediaries, and that the same nominal interest rate $i_{t}^{d}$ is available to all savers, and that a (possibly) different nominal interest $i_{t}^{b}$ is available to all borrowers. The key friction in the model is that households cannot engage in financial contracting, and it can only save or borrow through the financial intermediary sector which requires resources. Moreover, the spread between the deposit and lending rates fluctuates as a result of banks' lending activities creating a certain number of opportunities for borrowers to take out loans without being made to repay. Intermediaries are unable to distinguish the borrowers who will default from those who will repay and so must offer loans to both on the same terms. (It is assumed that intermediaries can accurately predict the fraction of loans that will not be repaid as a function of a given scale of expansion of their lending activity.) To perform the Monte Carlo experiment, we use five shocks: shocks to productivity, monetary policy, government spending, wage markup and financial intermediation (credit). We set the standard deviation of these five shocks such that each of them explain $20 \%$ of the analytical FEV of output. We take the rest of the parameter values from Curdia and Woodford (2010).

The on-line appendix lists the model equations for each DGP and the parameter values used and provides additional technical details on the model simulations. We generate 1000 datasets from both models that include the following variables: $y_{t}, \pi_{t}, R_{t}, S_{t}, C_{t}, \varepsilon_{t}^{C, D S G E}$. 
Here $y_{t}$ denotes real output, $\pi_{t}$ is the inflation rate, $R_{t}$ is the policy interest rate, $S_{t}$ is the spread between the lending rate and the policy rate, $C_{t}$ denotes the quantity of credit and $\varepsilon_{t}^{c, D S G E}$ is the credit supply shock. The length of the time-series is set to 1000, with the first 800 observations discarded to remove the influence of initial conditions.

The generated data is used to estimate 5 SVAR models described above: (1) a SVAR that identifies the credit supply shocks via sign restrictions implied by the Gertler and Karadi (2011) model - a negative credit supply shock is assumed to reduce output, inflation, the quantity of loans and the policy rate on impact and increase the spread between lending rates and the policy rate. (2) the SVAR with sign restrictions and the constraint that the credit supply shock maximises its contribution to the FEV of $C_{t}$ over a horizon of 40 quarters. (3) A recursive SVAR where the cumulated shock $\varepsilon_{t}^{c, D S G E}$ is included as a variable in the model. Following standard practice, the shock is ordered after output, inflation and the credit quantity but before the policy rate and the spread and thus has a contemporaneous impact on the latter two variables. Note that while this ordering is used in empirical work, it is not consistent with the DGP and the resulting responses are likely to be biased. Our aim is to check the magnitude of biases resulting from such mistakes related to ordering of the variables (4) A proxy SVAR model that uses $\varepsilon_{t}^{c, D S G E}$ as an instrument to identify the shock. (5) A switching SVAR that uses heteroscedasticity to estimate the contemporaneous impact matrix. The lag length for these models is chosen via the Schwarz criteria using a maximum lag of 4 . 

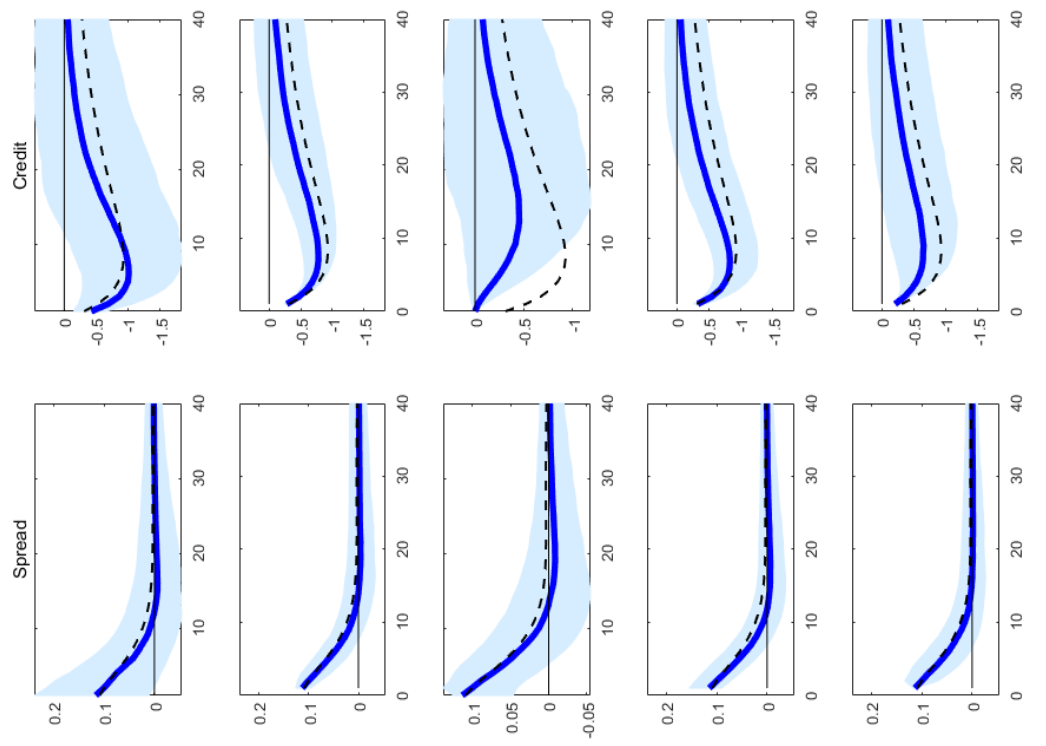

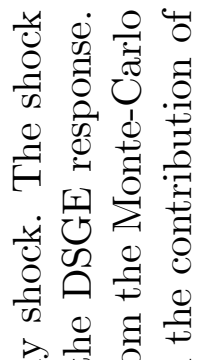

ती क्षै

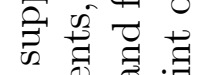

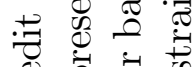

过选 000

ㅇ. 잉

娄

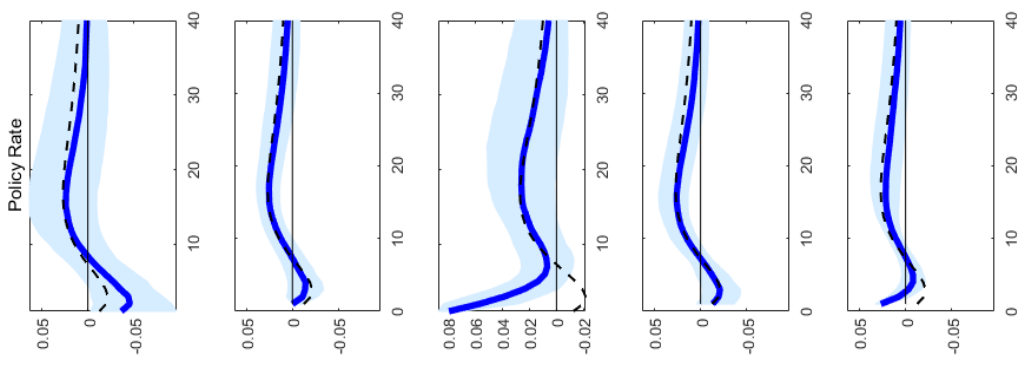

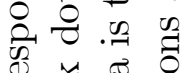

可

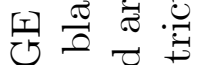

W

터

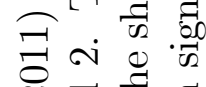

의

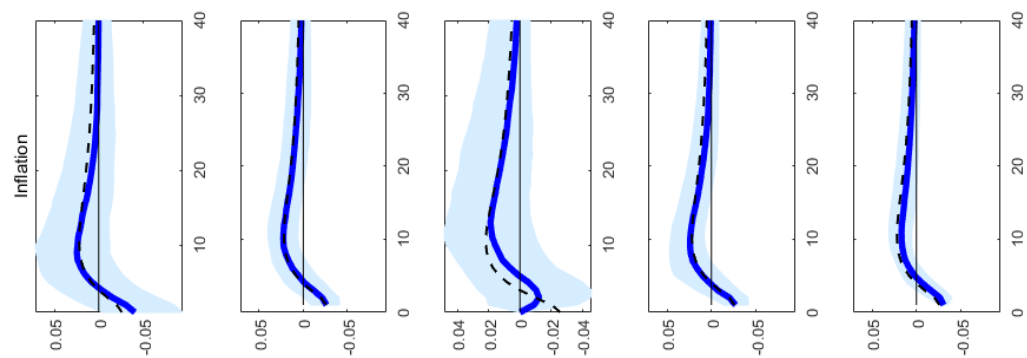

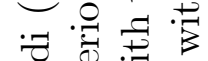

疋

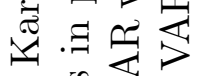

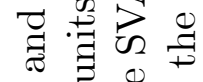

๘ี

苾苟

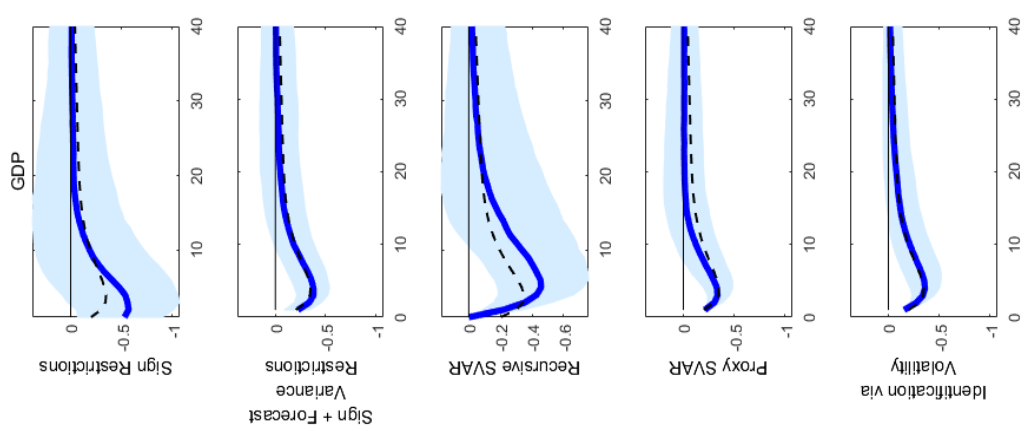

명

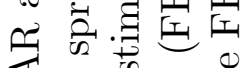

य 0 की

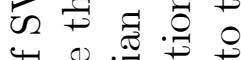

पै

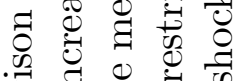

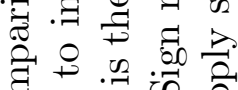

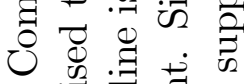

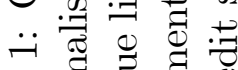

○ 킁 킁

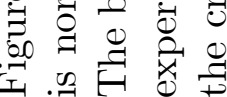



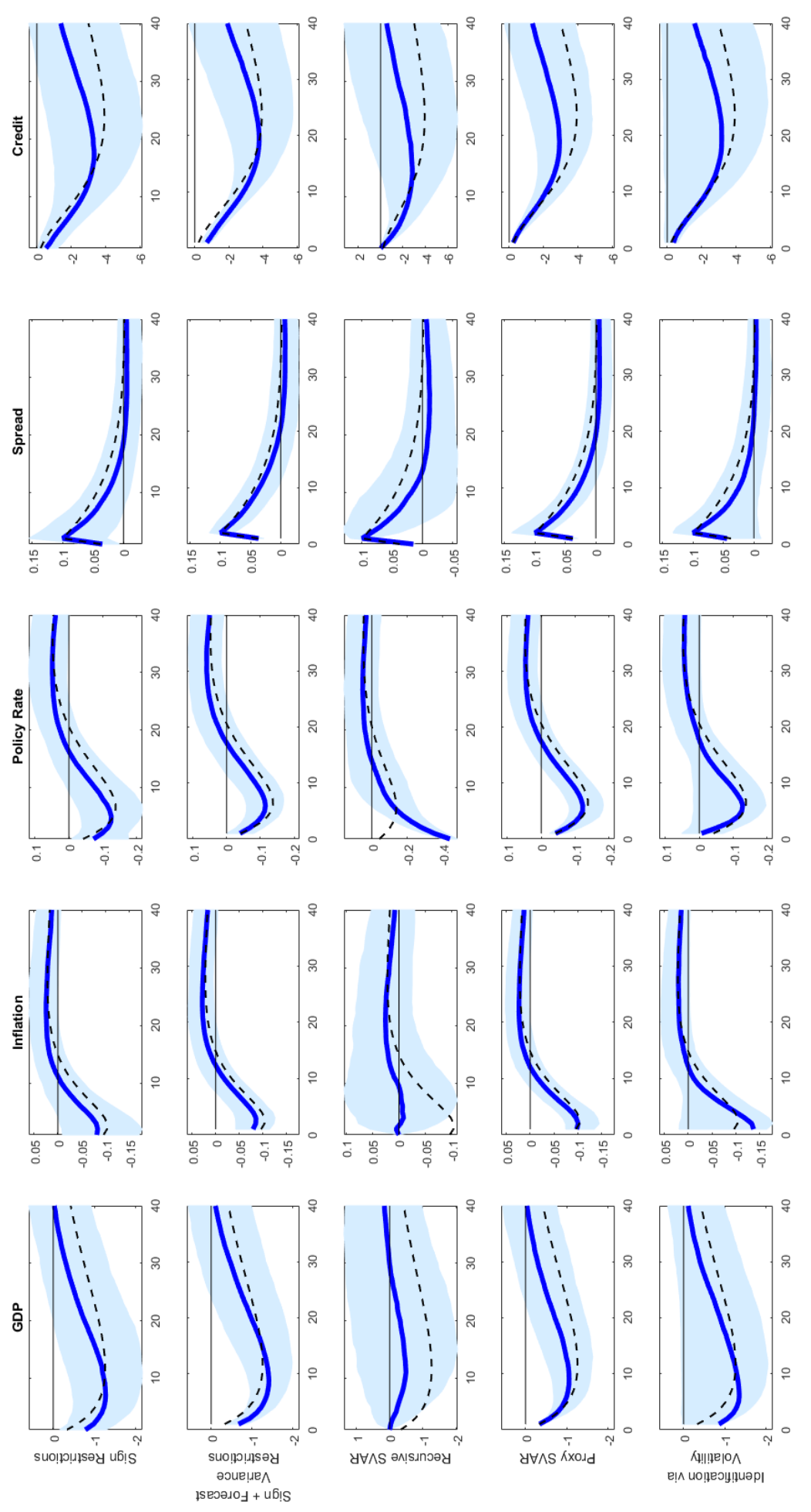

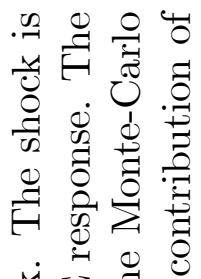

نـ

㐘

궁ํํ

की

清苛

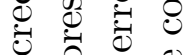

¿

$\circ \&$

๘)

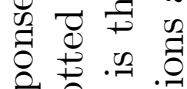

웡

푀 式 苛

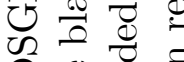

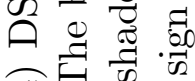

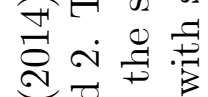

त்

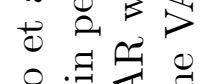

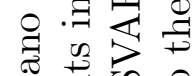

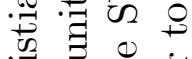

离

용

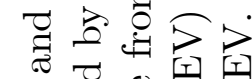

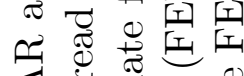

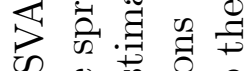

约过获。

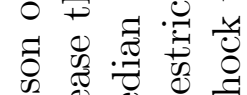

.

范. छ

ن뇨

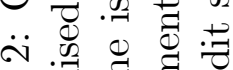

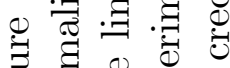

社 

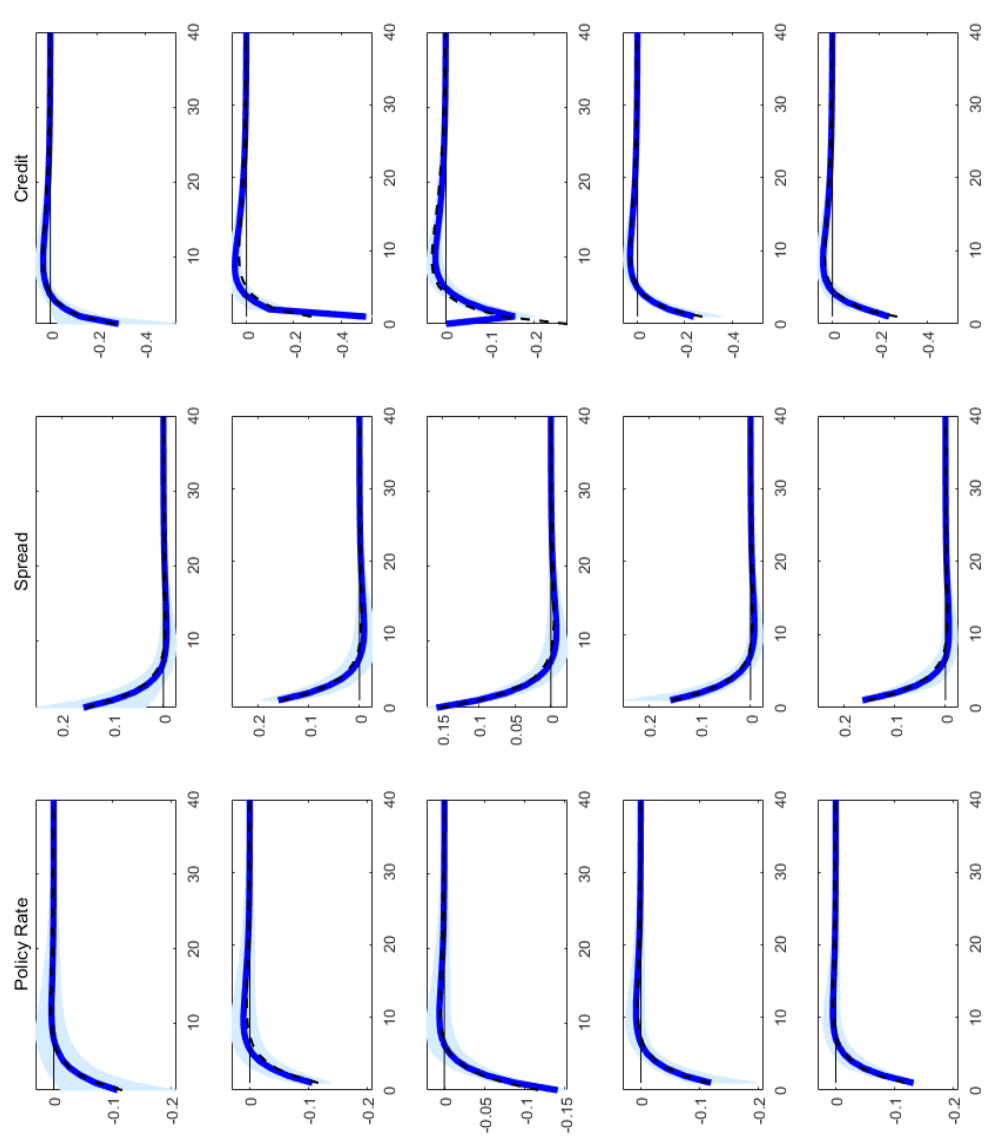

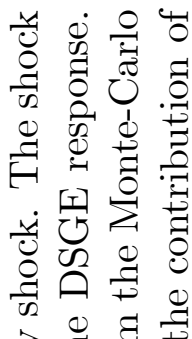

경영

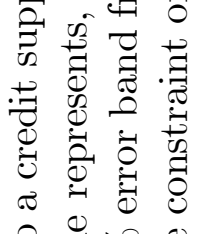

음의 잉

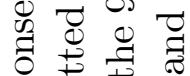

की

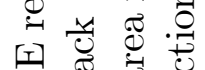

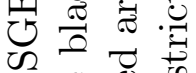

ค

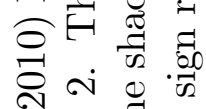

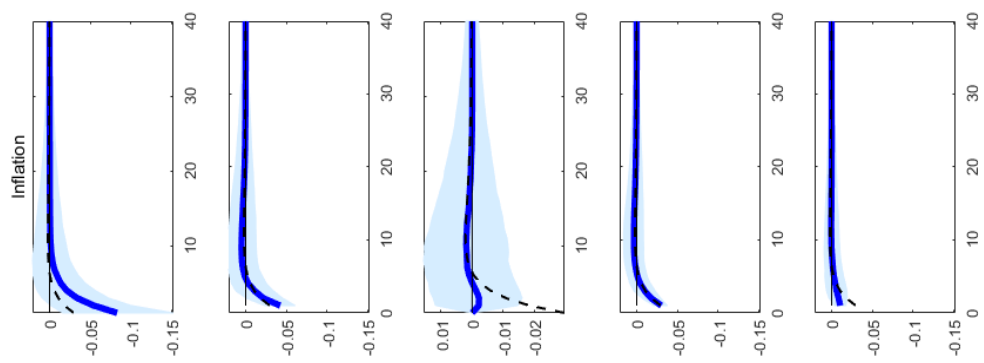

멤유

t)

묠

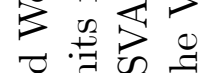

者 $\Xi 0$

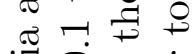

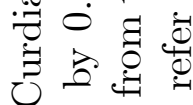

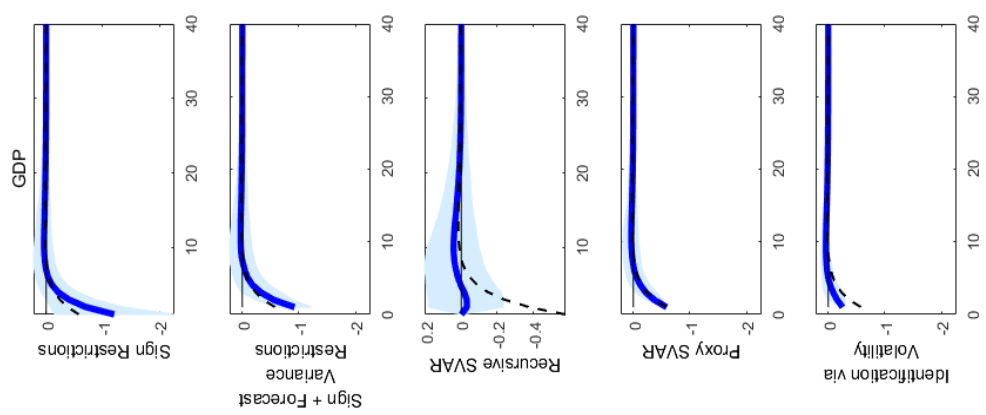

궁

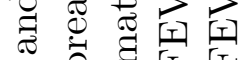

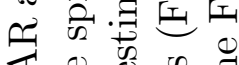

य के चै

级

पै

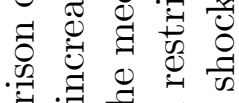

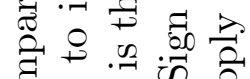

至

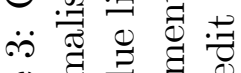

Ð

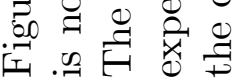




\subsection{Results}

Figure 1 compares the impulse responses obtained from each SVAR model with those implied by the DSGE model of Gertler and Karadi (2011). Results using the Christiano et al. (2014) model as the DGP are presented in figure 2 while figure 3 presents the results based on the Curdia and Woodford (2010) model. In the DGPs and the SVARs, the shock is normalised to increase the spread by 10 basis points to allow for a comparison of the transmission of this shock in these three cases.

The top two rows of the figures consider the performance of the SVAR with sign restrictions, without and with the constraint on the FEV, respectively. The median estimate from the pure sign restriction scheme is close to the true response for inflation and the interest rates. The estimated response of output and the credit quantity displays a bias at the medium and long horizons. More importantly, the uncertainty surrounding the median estimates is quite large, suggesting that the set of admissable models is wide. This appears to be a practical problem in this setting as the wide error bands prevent meaningful inference on key variables such as output. For example, at the six month horizon the response of output ranges from -1 percent to -0.05 percent using the Gertler and Karadi (2011) DGP, from -1.5 percent to -0.3 percent using the Christiano et al. (2014) model and -1.3 percent to -0.07 percent using the Curdia and Woodford (2010) model with each of these estimates admissable under the contemporaneous sign restrictions. The estimated response of the other variables shares this feature and highlights the point raised in Kilian and Murphy (2012) that additional restrictions may be required to pin down the results when using sign restrictions. ${ }^{1}$ This point is further re-enforced by the results presented in the second row of the figures. When the restriction on the FEV is added to the sign restrictions, the median estimate of the response improves and the admissable set shrinks. Note that for each variable, the median impulse response is close to the DSGE response and the bias in the estimate for output and credit is smaller. The restriction on the FEV reduces the set of admissable models and leads to a narrower range of estimates. For example, the output response at the 2 quarter horizon ranges now from -0.45 percent to -0.2 percent in the Gertler and Karadi (2011) model simulation, -1.1 percent to -0.6 percent using the Christiano et al. (2014) model and $-0.9 \%$ to $-0.2 \%$ using the Curdia and Woodford (2010) model. In the former experiment, in contrast to the pure sign restriction scheme, this extended model leads one to infer correctly that the effect of this negative shock is unambiguously contractionary at the one year horizon.

The third and the fourth rows of the figures present the estimates from the recursive and proxy SVARs, respectively. The recursive SVAR performs poorly with the median response very different from the DSGE response. The poor performance of this model is directly related to the fact that the zero restrictions imposed by this scheme are not consistent with the DSGE model. In the DGP, the credit shock has a non-zero impact on all variables. As a consequence, the response of output, inflation is biased in all experiments with the bias particularly severe when the DGP is the Christiano et al. (2014) or Curdia and Woodford

\footnotetext{
${ }^{1}$ Baumeister and Hamilton $\sqrt{2015}$ ) show how to implement such restrictions in the form of a prior belief.
} 
(2010) model. Similarly, the response of credit and the policy rate also diverges from the true response, with the estimated contemporaneous sign of the response incorrect in the experiment involving the Gertler and Karadi (2011) model. Overall, this suggests that the results using the recursive scheme can be highly sensitive to the ordering of the variables i.e. the impulse responses can be subject to large biases if the ordering is incorrect.

In contrast, the Proxy SVAR performs well. At short horizons, the median estimated responses are close to theoretical responses, with a slight bias in the output and credit response at longer horizons. Note also that the error bands are fairly narrow indicating that the responses are estimated with precision.

In sections 2.4 and 2.5 in the on-line appendix, we consider an additional experiment featuring the recursive and proxy SVAR where the proxy variable $\varepsilon_{t}^{c, D S G E}$ is assumed to be measured with error. In particular, in these experiments we define the proxy variable as $\varepsilon_{t}^{c, D S G E}+v_{t}, v_{t}^{\sim} N\left(0, \sigma_{v}^{2}\right)$ where we consider scenarios under which $\sigma_{v}^{2}$ is half and twice as large as the variance of credit shock. In both cases, the responses from the recursive SVAR display a large attenuation bias with the bias increasing in $\sigma_{v}^{2}$. In contrast, the measurement error has little effect on the performance of the proxy SVAR. This is because, in the proxy SVAR model, the instrument does not enter the VAR directly as an endogenous variable and therefore the estimates of the VAR parameters are unaffected by measurement error bias. ${ }^{2}$

The final row of the figures presents the results for switching VAR model. The VAR response for output is fairly close to the theoretical response. The sign of the inflation response matches that of the DSGE response. However, the VAR estimate of these responses is biased upwards in the case of the final two experiments. The estimated response of the policy rate displays the largest divergence from theory in the simulation based on the Gertler and Karadi (2011) model. The VAR response of this variable is positive over short horizons while the DSGE response is negative. This suggests that when using this identification scheme, it can be difficult to distinguish between the credit supply shock and a monetary policy shock, where the latter would imply a positive short-rate response. The performance of this scheme improves if the degree of change in the credit supply shock variance is increased. However, the scale of the increase required in this DGP to improve the performance of this identification scheme appears to be unrealistically large. ${ }^{3}$

Overall, the Monte-Carlo experiments suggest that the VAR with sign and FEV restrictions and the proxy SVAR display the best performance in identifying the credit supply shock. Identification via heteroscedasticity appears to be sensitive to the degree of the shift in the volatility of the structural shocks. Finally, the recursive scheme performs poorly and appears to be strongly affected by measurement error bias.

With these simulation results in hand, we take these SVAR models to the data and attempt to gauge the importance of the credit supply shock for the US economy.

\footnotetext{
${ }^{2}$ Using our DGPs, we find that $\sigma_{v}^{2}$ needs to be about 10 times larger than the variance of the credit shock for there to be a noticeable bias in the proxy SVAR responses.

${ }^{3}$ See section 2.3 in the online appendix.
} 


\begin{tabular}{llllll}
\hline & GDP growth & CPI Inflation & Lending growth & Spread & 3mth T-Bill \\
Credit Supply & $\leq 0$ & $\leq 0$ & $\leq 0$ & $\geq 0$ & $\leq 0$ \\
\hline
\end{tabular}

Table 1: Contemporaneous sign restrictions in the benchmark model

\section{The impact of credit supply shocks in the US}

In this section of the paper we use the structural VAR models discussed above to estimate the impact of credit supply shocks for the US. The basic data for the VAR models runs from 1973Q1 to 2013Q2 and, unless otherwise noted, includes the following variables: (1) Real private investment growth, (2) Real consumption expenditure growth, (3) Real GDP growth, (4) CPI inflation, (5) Growth of total lending to households and private non-financial corporations, (6) the spread of a composite lending rate over the 3-month treasury bill rate, (7) the 3-month treasury bill rate, (8) the Chicago Fed financial conditions index and (9) the measure of economic uncertainty developed by Jurado et al. (2015). ${ }^{4}$ The variables included in the VAR model cover the real and monetary sectors of the economy and also try to account for the role played by shocks to the financial sector and uncertainty, both of which have been identified as being important for economic fluctuations (see Bloom (2009) and Alessandri and Mumtaz (2014) amongst others). The lag length for all VAR models is chosen via the Schwarz criteria using a maximum lag of 4 and all growth rates are defined in quarterly annualised terms.

\subsection{Impulse responses and variance decomposition}

\subsubsection{A VAR with sign restrictions and constraints on the FEV}

The sign restrictions that we use to identify the credit supply shock are summarised in table 1. These restrictions are implied by Gertler and Karadi (2011) model and are robust across different calibrations. ${ }^{5}$

Given the superior performance of the sign restriction algorithm with restrictions on the forecast error variance in the Monte-Carlo experiment described above, we also impose the condition that the credit supply shock maximises its contribution to the forecast error variance of lending growth over a horizon of 40 quarters.

The top row of figure 4 plots the impulse responses obtained from this model. The shock is normalised to increase the credit spread by 10 basis points on impact. The figure shows that this shock has a large and persistent negative impact on the economy. Credit growth declines by $0.8 \%$, the uncertainty index increases and the FCI rises on impact signalling a deterioration of financial conditions. Investment growth declines by about $2 \%$, with consumption and GDP

\footnotetext{
${ }^{4}$ Appendix A provides details on data sources and construction.

${ }^{5}$ A figure that shows the range of impulse responses from the Gertler and Karadi (2011) model obtained by using a grid for the calibrated parameters is available in the on-line appendix.
} 
growth falling by about $0.4 \%$ to $0.5 \%$. Note that it takes about 3 to 5 quarters for the impact on these variables to dissipate. The decline in inflation and the short-term interest rate in response to this shock is estimated to be more persistent.

Table 2 shows that the contribution of the credit supply shock to the FEV of GDP and consumption growth and inflation is estimated to be about $20 \%$ at the one year horizon, while the estimates suggest that this shock was less important for investment growth fluctuations. One possible explanation for this result is that the identified credit supply shock may reflect credit conditions of households and its impact on investment is not fully apparent using aggregate data. In fact, if we replace aggregate investment with residential investment, the contribution from the credit supply shock is larger and more at par with the contribution to consumption providing some evidence for this conjecture. ${ }^{6}$

It is also interesting to note that the shock explains a large proportion of the FEV of inflation and the short-term interest rate at the 1 year and 5 year horizons. This possibly captures the fact that large drop in GDP growth and inflation in the face of this shock induces a response from the monetary authorities, resulting in fluctuations in the short-term interest rate.

\footnotetext{
${ }^{6}$ These results are available on request from the authors.
} 

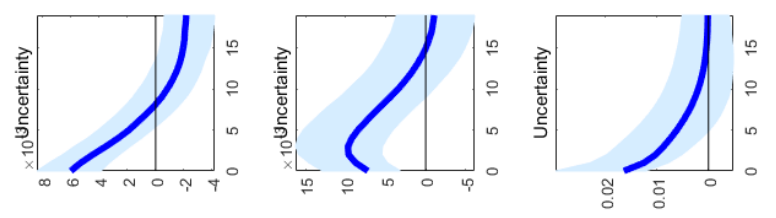

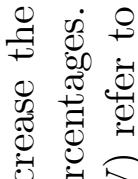
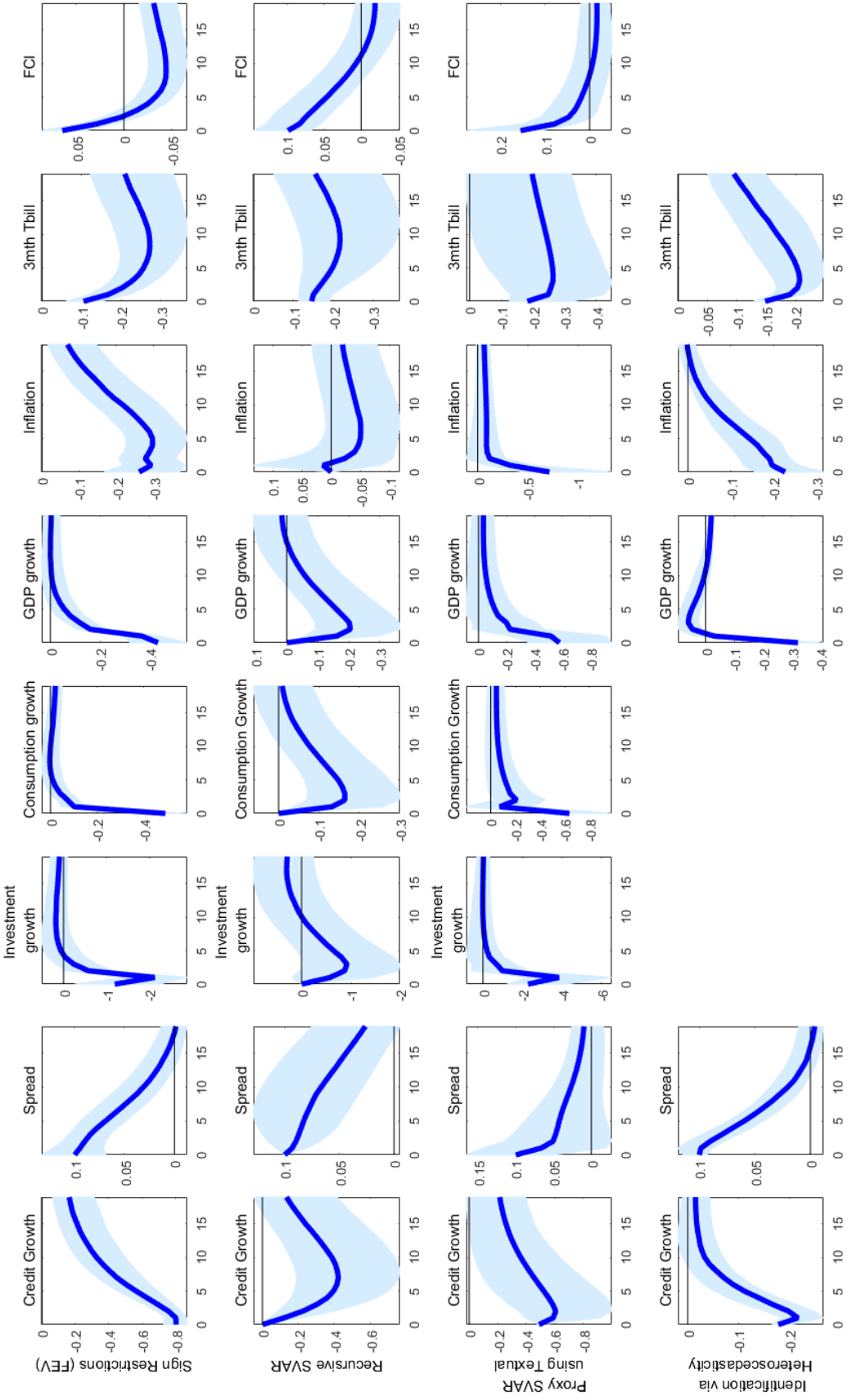

.

。回远

D

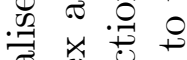

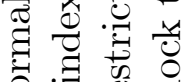

.

. 20.

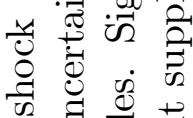

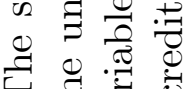

Eझ需

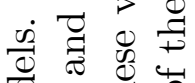

च

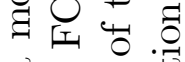

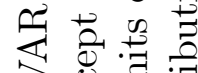

的离霖

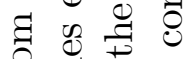

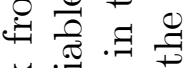

过菅芯

๙

궁혀

के छे

啳

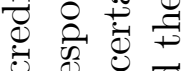

○

$\circ$ 텅

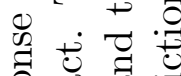

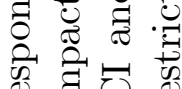

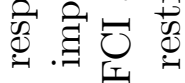

की

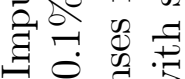

1 更

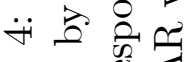

蛋怘

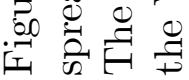




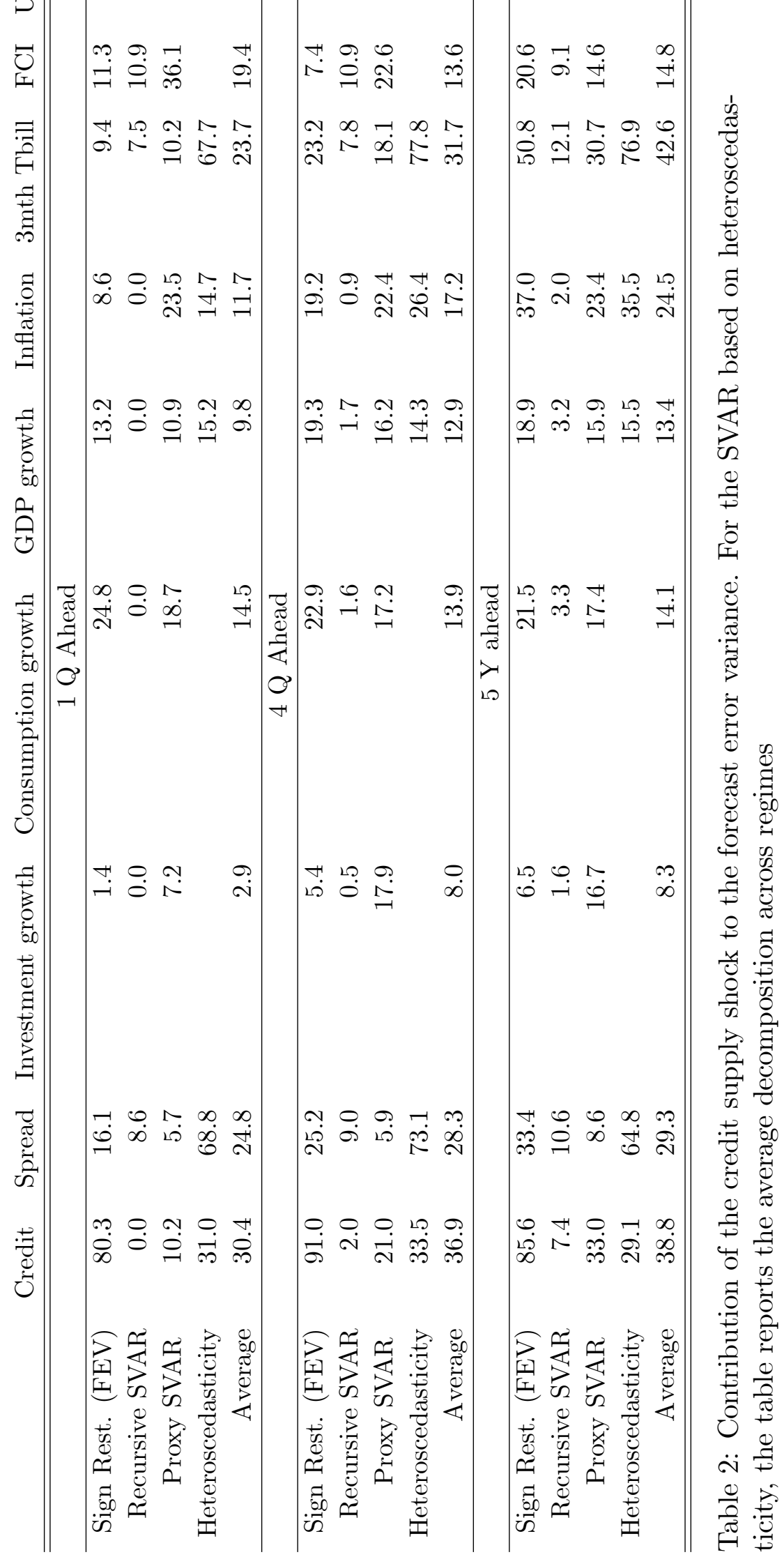




\subsubsection{Recursive SVAR models}

A number of proxies for credit supply shocks have been proposed in a growing empirical literature. As discussed above, a common approach is to include these proxies in a VAR and treat the orthogonolised shock to the proxy variable equation as an approximation of the credit supply shock. Prominent recent examples of such proxy variables include: (1) the excess bond premium (EBP) proposed in Gilchrist and Zakrajsek (2012), (2) the measure of bank lending shocks (BCDZ) calculated by Bassett et al. (2014), (3) innovations to the financial conditions index calculated by Jermann and Quadrini (2012) and (4) the risk shock (CMR) from the DSGE model of Christiano et al. (2014). ${ }^{7}$ In addition to using these proxies, we propose a textual measure of credit supply shocks in the spirit of similar measures developed to estimate changes in uncertainty (see Baker et al. (2017)). This measure is based on a search for the words 'credit crunch' and 'tight credit' using 9 US newspapers. ${ }^{8}$ An index is then built by counting the number of occurrences of the words of interest. Note that as discussed in Appendix A, these proxies are available for different periods over our main sample.

Figure 5 plots the credit shock proxies that described above. The temporal evolution of the proxies is similar with each pointing to tight credit conditions during the early and the mid-1980s, the early 1990s and 2000s and during the recent recession in 2009. We include each of these proxies in our VAR model and identify the credit supply shock via a Cholesky decomposition. We use a standard ordering of the variables following studies like Gilchrist and Zakrajsek (2012) - the shock proxy is ordered after investment growth, consumption growth, GDP growth, inflation and credit growth and before the spread, the short-term rate, FCI and uncertainty index. This ordering assumes, therefore, that the credit supply shock can have an immediate impact on financial variables and uncertainty but affects macroeconomic variables with a lag. Note also that as these proxies are available over different sub-samples, the estimation sample for each model differs. See Appendix A for exact dates.

We show in section 3.1 of the on-line appendix that the median responses are similar in magnitude when the proxy is assumed to be EBP, CMR or BCDZ. Shocks to JQ and the textual proxy suggest a much smaller response of key variables like GDP growth. In addition, the model with EBP and the textual proxy produces large error bands and the null hypothesis of a zero response for all variables cannot be rejected. In the second row of figure 4. we show the average response from the models that produce non-zero responses over, at least, some of the horizon-i.e. the VAR that includes JQ, BCDZ and CMR. On average, the recursive SVAR suggests that the decline in credit growth, inflation and real variables is smaller than suggested by the SVAR with sign restrictions. For example, the magnitude of the fall in investment growth, consumption growth and GDP growth is estimated to be about half of the decline suggested by the SVAR with sign restrictions. Note also that

\footnotetext{
${ }^{7}$ Of course, there are numerous other measures proposed in this literature. Our aim is to present results based on the most recent contributions.

${ }^{8}$ The newspapers included in the search are the Boston Globe, Chicago Tribune, Dallas Morning News, LA Times, Miami Herald, New York Times, San Francisco Herald, USA Today and the Washington post.
} 


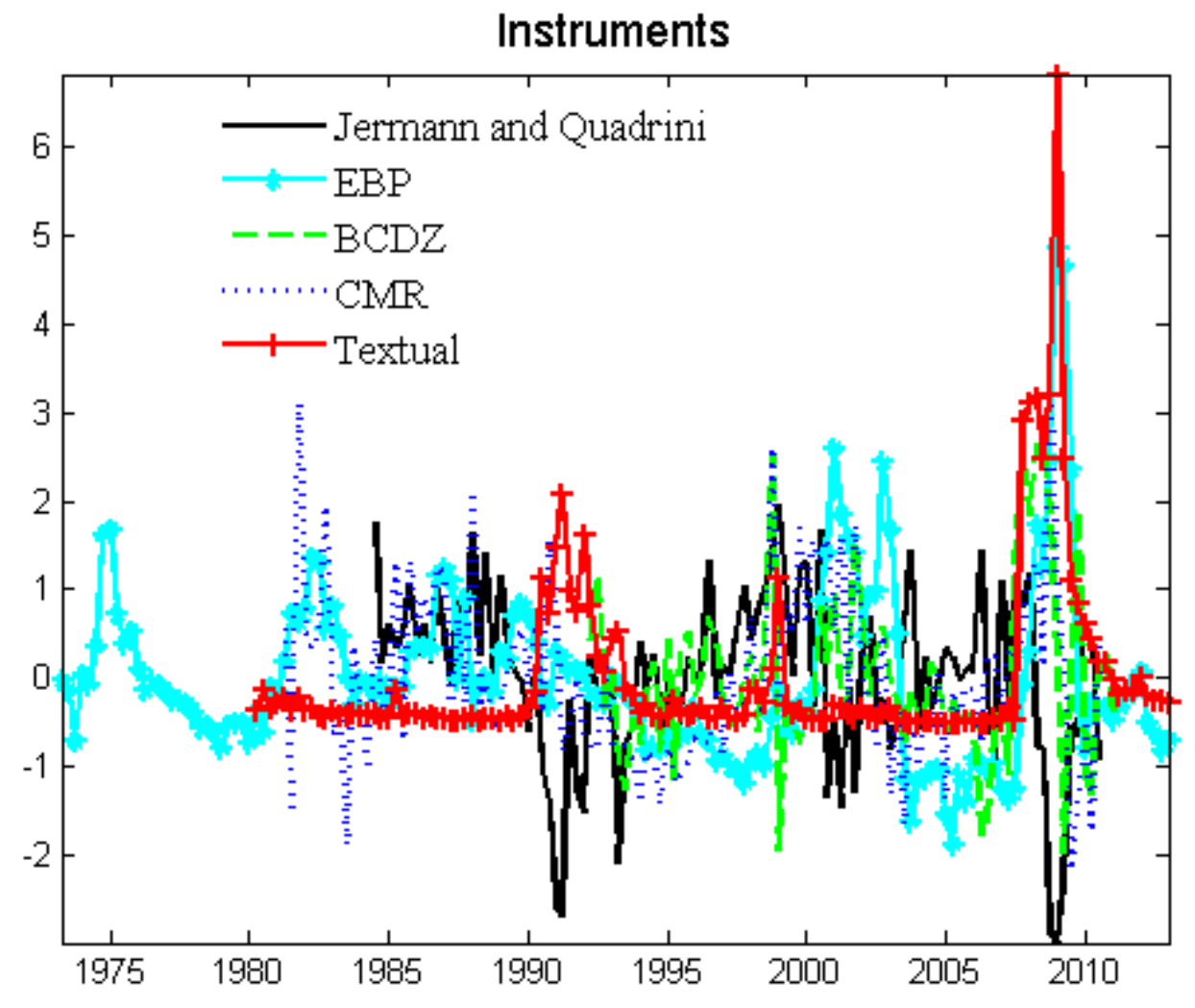

Figure 5: Proxies for credit supply shocks. Apart from the Jermann and Quadrini (2012) measure, higher values represent an adverse shock. 


\begin{tabular}{lll} 
& $R_{M}$ & $F$ \\
\hline \hline JQ & 0.50 & 13.1 \\
EBP & 0.10 & 2.36 \\
BCDZ & 0.15 & 3.5 \\
CMR & 0.2 & 3.82 \\
Textual & 0.18 & 5.5 \\
\hline \hline
\end{tabular}

Table 3: Reliability Statistic and the first stage F statistic for proxy variables

in the recursive model the trough in the responses occurs after a year, a feature that is different from the results obtained via sign restrictions. This delayed effect appears to be the result of the zero restrictions imposed on impact on these variables. Note that variables that react contemporaneously to the credit shock (the short-term interest rate, FCI and the uncertainty index) have responses comparable in magnitude to those obtained from the SVAR with sign restrictions. This suggests that the assumptions inherent in the recursive identification scheme can have important implications for the magnitude and dynamics of the resulting responses. In addition, table 2 shows that the one year contribution of the credit supply shock to the FEV calculated using the recursive SVAR is substantially smaller for investment growth, consumption growth and GDP growth compared to other SVAR models.

\subsubsection{Proxy SVAR models}

Including these proxies directly in an SVAR can result in biased responses if the proxy is mis-measured. Given that the credit supply shock is unobserved, a degree of measurement error is inevitable. Therefore, we also consider proxy SVAR models that use these measures as instruments to identify the credit supply shock rather than endogenous variables in the VAR. In theory, one can use each of these as an instrument to estimate the proxy SVAR model. However, these proxies differ in their 'reliability' as an instrument. We therefore proceed in two steps: we first analyse the suitability of each instrument and then use the best performing proxy in the final SVAR model.

We check the reliability of the instrument using two statistics. First, following Stock and Watson (2012), we consider the F-statistic in the 'first-stage' regression in equation 4. A large estimated value of the F-statistic is associated with a strong instrument. In addition we calculate the reliability statistic proposed by Mertens and Ravn (2014). The authors define reliability $R_{m}$ as the squared correlation between the proxy variable and the underlying structural shock of interest. Their proposed estimator takes values between 0 and 1 with larger values indicating higher reliability.

Table 3 shows the estimated $\mathrm{F}$ statistic and the value of $R_{m}$ for each instrument. The Fstatistic and the reliability measure are estimated to be the highest for the measure proposed in Jermann and Quadrini (2012). The textual measure also appears to be a moderately strong instrument on the basis of the F-statistic but has a relatively low $R_{M}$.

It is interesting to consider the sample correlation between the shocks identified by each 
instrument. As discussed in Stock and Watson (2012), if two instruments are identifying the same underlying shock, then the correlation of the estimated shock will be one in the population. A correlation matrix reported in section 3.2 of the on-line appendix shows that the credit shock estimated using the Jermann and Quadrini (2012) proxy is highly correlated with those obtained using the EBP and moderately correlated with the shock estimated using the textual measure. In contrast, this shock has a near-zero correlation with the innovation estimated using the BCDZ measure. This suggests that these two instruments potentially identify very different shocks. In contrast, the shock estimated using the textual measure displays a correlation of 0.4 to 0.8 with the remaining three estimates of this shock. This indicates that the shock identified using the textual measure shares common features with the shocks identified using the remaining proxies and is less likely to be related to a different economic concept.

As pointed out in Stock and Watson (2012), the possible correlation between the identified shock and other shocks (i.e. those identified using a different set of instruments) provides additional information on the strength of the identification of the shock of interest. In section 3.2 of the on-line appendix we consider the correlation between the credit shocks and estimates of a productivity shock, a monetary policy shock and an uncertainty shock, respectively. The productivity shock is identified by using the estimated productivity shock from the Smets and Wouters (2007) model. The monetary policy shock is estimated using the measure proposed in Romer and Romer (2004). Finally, innovations to the Baker et al. (2017) index (calculated as residuals to an AR(2) model) are used to identify the uncertainty shock. The estimated correlations suggest that the credit shock identified via the Jermann and Quadrini (2012) instrument has a correlation of 0.7 with the productivity and uncertainty shock. This suggests that this shock is not exclusively an innovation to credit supply, but instead is a composite of different economic innovations. In contrast, the credit supply shock estimated using the textual measure (which ranks second in terms of instrument strength) has a low correlation with the productivity and monetary policy shock and appears only moderately associated with the uncertainty shock.

In summary, the analysis of instrument strength in conjunction with the correlations described above suggests that the textual measure is a potential instrument to be used in the final SVAR model. While this instrument is not ranked the highest in terms of the F-statistic, there appears to be less evidence that the identified shock is related strongly to shocks other than credit supply. The same claim cannot be made about the shock identified via the Jermann and Quadrini (2012) instrument. We therefore use the textual proxy in the final model.

The third row of figure 4 presents the impulse responses obtained from the proxy SVAR using the textual proxy. The estimated decrease in inflation, investment, consumption and GDP growth is estimated to be larger than the estimates from the recursive SVAR and the SVAR with sign restrictions. The comparison with the recursive SVAR is especially interesting. Recall that when this proxy is added directly to the model and the shock identified via a Cholesky decomposition, the resulting responses are indistinguishable from 
zero. This again highlights the potential biases that may arise by using proxies directly and assuming a recursive identification scheme.

The contribution of this shock to the FEV of GDP growth one year ahead (see table 2) matches the estimates obtained from the SVAR with sign restrictions but is substantially larger than the estimate from the recursive SVAR. Notice also that in this model the credit supply shock makes a sizeable contribution to the FEV of investment growth, FCI and the uncertainty measure, with these estimates larger than those obtained via the SVAR with sign restrictions. As in the case of the SVAR with sign restrictions, the credit supply shock makes an important contribution to the FEV of inflation and the short-term interest rate at long horizons.

\subsubsection{Identification through heteroscedasticity}

Due to computational constraints, we estimate a parsimonious version of the model containing only the key variables when considering identification of the credit supply shock through changes in the variance. The benchmark 9-variable VAR model has a large number of parameters and, given the limited time-series available, this makes it difficult to obtain reliable maximum likelihood estimates of the parameters. In particular, the error bands around the estimated impulse responses are very large. This latter problem makes it difficult to distinguish among impulse responses to different shocks and thus makes it harder to assign an economic interpretation to them. Given these concerns, we consider a five-variable VAR model that contains GDP growth, CPI inflation, credit growth, spread and the short-term interest rate and allow for the possibility of up to three regimes.

The number of regimes is an important specification choice for this model. As shown in section 3.3 of the on-line appendix, model selection criteria such as Akaike, Schwarz and the deviance information criteria clearly reject a linear VAR model, and suggest that a three regime model fits the data best. There is also some evidence that the assumption of a stateinvariant contemporaneous impact matrix is supported by the data. After estimating the three-regime VAR model, we investigate if the diagonal elements of $\Lambda_{2}$ or $\Lambda_{3}$ are distinct, i.e. we check the condition for identification. As shown in the on-line appendix (section 3.3), there is fairly strong evidence that this condition is satisfied. Next, we examine the impulse responses to the five shocks in the model in order to label them from an economic point of view. It is clear that the shock to the spread equation produces responses that are consistent with those obtained from the DSGE model. The responses to other shocks, on the other hand, are not consistent with theory. With this evidence in mind, we label this shock the credit supply shock.

The bottom row of figure 4 plots the estimated responses to the credit supply shock. The GDP growth, inflation and T-Bill response displays persistence similar to that obtained from SVAR with sign restrictions, but appears less persistent than the estimates from the recursive and proxy SVARs. In terms of magnitude, the contemporaneous estimates are close to the peak estimates from the recursive SVAR and the VAR with sign restrictions, but generally smaller than those obtained from the proxy SVAR model. The bounce-back in GDP growth 

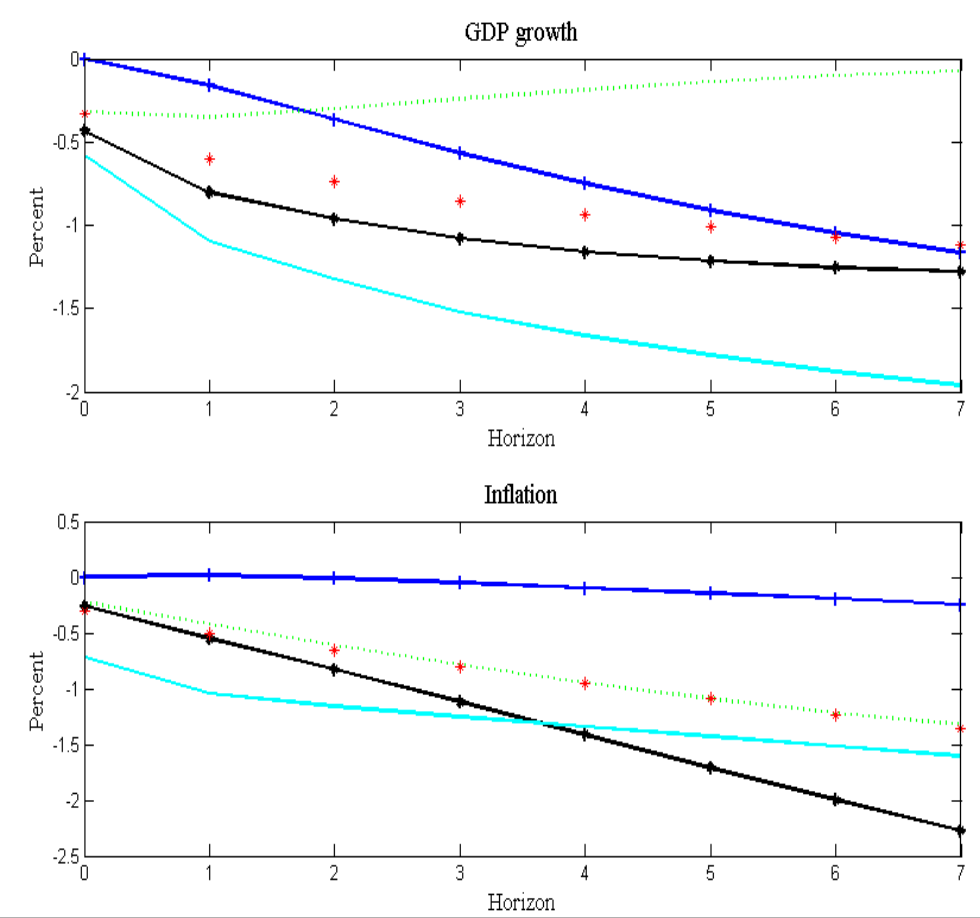

Sign Restrictions ——Recursive —- Proxy $\cdots \cdot \cdots \cdot . \cdot$ Identification via heteroscedasticity * Average Response

Figure 6: The cumulated impulse response of GDP growth and inflation to a credit supply shock. The shock is normalised to increase the credit spread at the one year horizon.

two quarters after the shock implies that the cumulative impact of the shock is estimated to be much smaller in this model.

While the contribution of this shock to the FEV of GDP growth and inflation is broadly similar to the VAR with sign restrictions and the proxy SVAR, the shock estimated from the switching VAR appears to be substantially more important for the spread and the short-term interest rate (see table 2).

\subsection{How big is the impact of the credit supply shock?}

Figure 6 shows a comparison of the cumulated responses of GDP growth and inflation to a credit supply shock obtained from the four SVAR models. We focus on these two variables as these are of primary interest to policy makers. Consider the response of GDP growth. It is clear that at the one year horizon, the proxy SVAR and VAR with sign restrictions suggest a fairly similar total response of GDP of around $-1.2 \%$ to $-1.7 \%$. The average response from the recursive SVARs suggests a smaller decline in GDP at this horizon, estimated at $0.75 \%$. As noted above, this may reflect the zero restriction on the contemporaneous response imposed under this scheme or a possible attenuation bias resulting from errors in variables. Finally, notice that the VAR identified via heteroscedasticity indicates the smallest response of GDP 
growth at this horizon, estimated at $-0.2 \%$. Given that the initial response of GDP from this model is broadly in line with estimate from the SVAR with sign restrictions, the difference at longer horizons appears to be driven by the fact that the estimated response from the switching VAR is much less persistent than suggested by the other models.

At the one year horizon, the cumulated response of inflation from the proxy SVAR and the VAR with sign restrictions is the largest suggesting a decline in inflation of about $1.4 \%$. As in the case of GDP growth, the recursive and the heteroscedastic VAR, indicate a smaller response ranging from $-0.1 \%$ in the former case to $-0.9 \%$ in the latter.

On average across models, a credit supply shock that raises the spread by 10 basis points leads to a cumulative decline of $0.94 \%$ in annualised GDP growth one year after the shock. The average decline in inflation at this horizon is similar and estimated at $0.95 \%$. The FEV decomposition in table 2 suggests that, on average, the credit supply shock explains about $13 \%$ of the FEV of GDP growth and $17 \%$ of the FEV of inflation at the one year horizon.

While the uncertainty around these estimates is large, these average results are largely driven by the impulse responses from VAR models that perform well in the Monte-Carlo experiment conducted above. Therefore, on balance, we can conclude that, ceteris paribus, the credit supply shock can have large effects on the macroeconomy.

These results are broadly consistent with estimates reported in related SVAR studies such as Gambetti and Musso (2017) and Gilchrist and Zakrajsek (2012). The peak impact of a comparable credit supply shock in these two studies ranges from $-0.8 \%$ to $-1.3 \%$ for GDP and $-1.2 \%$ to $-1.3 \%$ for CPI, estimates similar to those reported in Figure $6 .{ }^{9}$ Similarly, these studies suggest that credit supply shocks are important for the FEV of these variables with contributions of $10 \%$ to $20 \%$ reported for both variables. Again, these estimates are consistent with the results presented above.

If the end of the sample is restricted to 2006Q4, the response and FEV contributions from the main SVAR models remains fairly similar to the benchmark for GDP growth: on average, the proxy SVAR and the VAR with sign restrictions suggest that the cumulated decline in GDP growth is $0.9 \%$ at the one year horizon, while the contribution of the credit supply shock to the FEV of this variable is $16 \%$. The response of inflation is estimated to be slightly lower than benchmark, with the cumulative decline of $0.6 \%$. Similarly, the contribution of the credit supply shock to inflation FEV at the one year horizon is estimated to be $9 \%$ on average across these models. This difference from benchmark is largely driven by the results from the proxy SVAR which delivers smaller responses of inflation. One explanation for this result may be that restricting the sample to the pre-2007 period removes a large amount of variation in the textual measure and reduces its strength as an instrument for credit supply shocks. ${ }^{10}$

\footnotetext{
${ }^{9}$ These estimates are based on the results of Gilchrist and Zakrajsek (2012) and Gambetti and Musso (2017) which are normalised to imply a 10 basis point increase in the lending spread and the excess bond premium, respectively after a credit supply shock.

${ }^{10} R_{m}$ and the F-statistic drop to 0.04 and 1.08 respectively over the pre-2007 sample.
} 

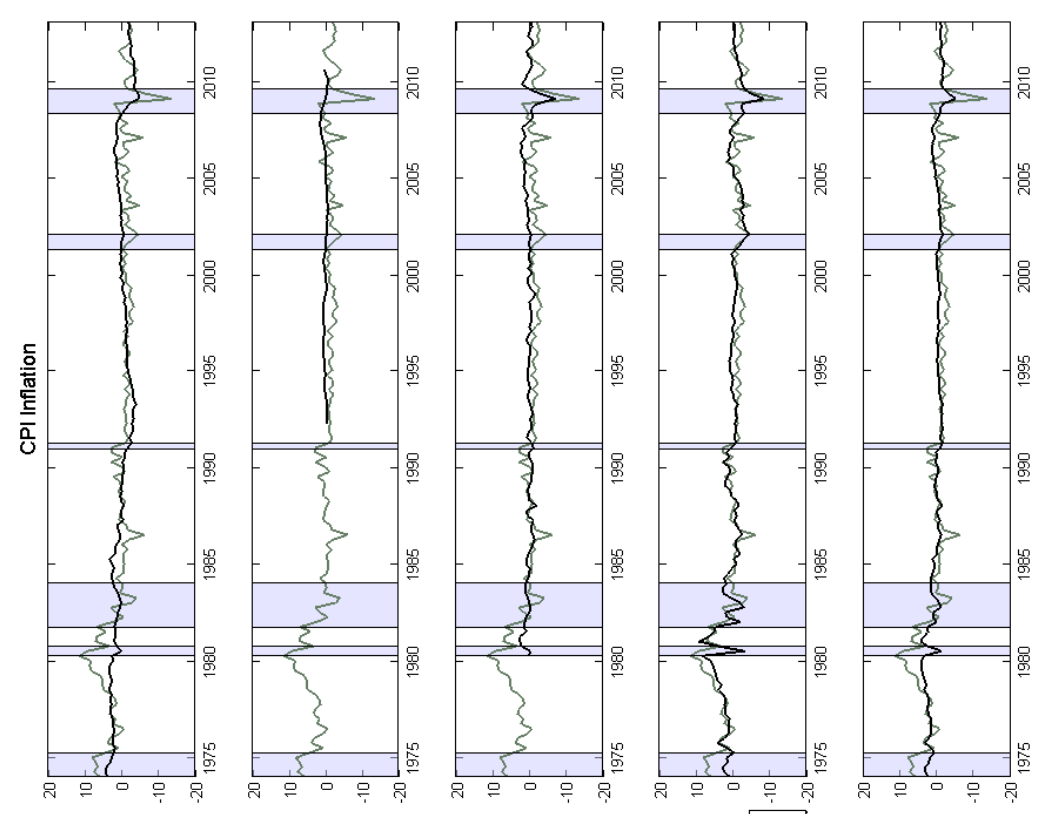

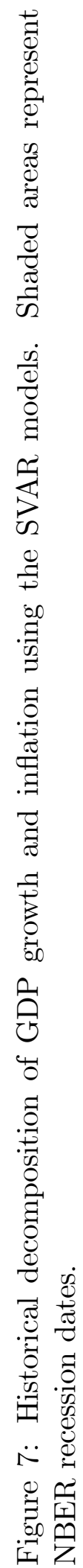
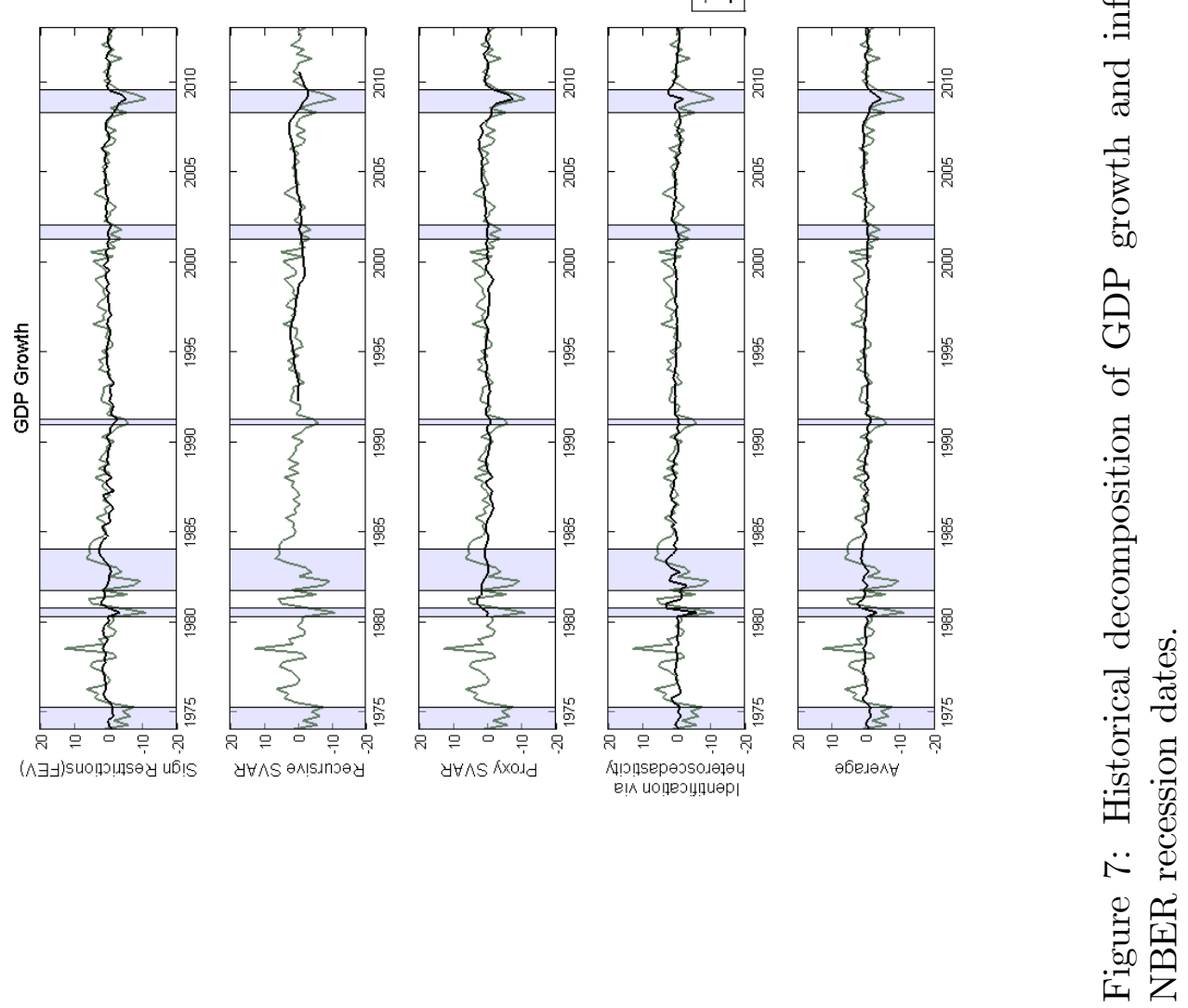
How important was the credit suply shock in driving GDP growth and inflation over the recent past? Figure 7 plots the data on these variables, together with the counterfactual estimates of the data from the four SVAR models under the assumption that only the identified credit supply shock is operational. The SVAR with sign restrictions and the heteroscedastic VAR suggest that the credit supply shock played a role in the decline of GDP during the two recessions of the early 1980s, with the latter model also indicating that this shock was important in driving inflation over that period. Similarly, there is some indication that during the recession following the savings and the loans crisis during the late 1980s, the credit supply shock makes a contribution to the downturn in GDP growth. However, it is during the Great Recession that the contribution of this shock appears to be largest as indicated by all models. In fact, the average estimates in the last row of the figure suggest that the trough of the decline in GDP growth in 2009 would have been halved if the credit supply shock had been absent. ${ }^{11}$ Similarly, the sharp decline in inflation over this period would have been ameliorated, if the impact of this shock had been absent.

It is interesting to note that the estimated magnitude of the effects on key variables is fairly similar to those obtained by recent DSGE based studies (see for example Gerali et al. (2010), Del Negro et al. (2013), Christiano et al. (2014) and Del Negro et al. (2015) among others). ${ }^{12}$. The average dynamic effect of the credit supply shock on GDP growth implied by the SVAR analysis seems to lie well within the range of estimates implied by the above DSGE studies. However, the SVAR inflation response is higher than what is implied by DSGE models. The theoretical inflation response to a credit supply shock tends to depend crucially on the specification of the model. For instance, the absence of financially constrained households reduces the demand effect on inflation (as consumption is the largest GDP component) and, consequently, leads to a smaller inflation reaction relative to the case where these agents exist in the model (see (Pinter et al., 2013)). The analysis of Del Negro et al. (2015) illustrates that the slope of the price Philips curve also influences the inflation response after a shock. Furthermore, in the presence of working capital type frictions (see (Gerali et al., 2010)) inflation can increase after a negative credit supply shock. Christiano et al. (2014) show that credit supply shocks have played a significant role in explaining GDP historically. Interestingly, the importance of the shock rises during the recessions and this is also supported by the analysis in Gerali et al. (2010) for the Great Recession. These results are in line with the SVAR inference.

\section{Conclusions}

A growing empirical literature has proposed several SVAR models to estimate the impact of innovations in credit supply. In this paper we examine the performance of these SVAR models and try to establish a consensus view of the importance of credit supply shocks. Using

\footnotetext{
${ }^{11} \mathrm{~A}$ similar result is obtained if these estimates are considered on a cumulated basis.

${ }^{12} \mathrm{By}$ a credit supply shock we refer only to the unanticipated component of the 'risk' shock in Christiano et al. (2014)
} 
a Monte-Carlo experiment, we find that the SVAR with sign and FEV restrictions and the Proxy SVAR model can recover the true impulse responses to credit supply fairly accurately. Identification through heteroscedasticity is found to work well when the credit supply shock is sufficiently volatile. In contrast, the recursive identification scheme suffers from a myriad of inaccuracies and biases.

When applied to a US dataset, the SVAR models that perform well in the Monte-Carlo experiment suggest, on average, that the impact of credit supply shocks is fairly large and in line with DSGE based evidence. A shock that raises the spread by 10 basis points is found to have a cumulated negative impact of about $1 \%$ on GDP growth and inflation at the one year horizon. At this horizon, the shock explains about $13 \%$ of the FEV of GDP growth and $17 \%$ of the FEV of inflation on average across the SVAR models. The historical decomposition suggests that the credit supply shock was responsible for a large proportion of the decline in GDP growth and inflation during the Great Recession.

These results have important implications for policy makers. The importance of credit supply shocks for economic fluctuations underlines the need for macro-prudential policy to mitigate negative externalities from the financial sector. This could involve the use of tools such as regular stress testing of banks' balance sheets and countercyclical policies that aim to reduce credit growth in a boom and alleviate a shortage of credit during a recession. At the international level, there has been progress on this front in the shape of Basel III agreement which requires bank capital requirements to be pro-cyclical. In addition, central banks such as the Bank of England have introduced direct schemes to encourage bank lending during periods of credit crunch. One interesting avenue for future research is to model the transmission mechanism of such policies and investigate their impact on the transmission of credit supply shocks.

\section{Appendix A: Data}

- Loans to nonfinancial private sector Source: Flow of Funds Accounts of the United States: www.federalreserve.gov/releases/z1/ current/

This is constructed as the sum of nominal outstanding amounts of loans to households (flow of funds series FL154104005.q minus flow of funds series FL163162005.q) and loans to non-financial corporations (flow of funds series FL144104005.q minus sum of FL103169100.q, FL103163003.q and FL103162005.q).

- Composite lending rate. This is constructed as a weighted average of interest rate charged on loans to non-financial corporations and households. The weights are derived using the amounts outstanding.

The interest rate charged on loans to households is a weighted average of the 30 year Mortgage rate (taken from Federal Reserve economic data (FRED), code MORTG), the rate 
on loans for new autos, the rate on credit cards and the rate on personal loans at commercial banks. The latter 3 rates are available from the Federal Reserve Board website with codes RIFLPBCIANM48_N.M, RIFSPBCICC_N.M and RIFLPBCIPLM24_N.M. The series RIFSPBCICC_N.M is available from $199 \overline{4}$ onwards and is extended backwards using the average growth rate of the other two rates. The weights are derived using the amounts outstanding of each type of loan.

The interest rate on loans to non-financial corporations is calculated as the weighted average of prime loan rate (FRED code MPRIME) and the Commercial and Industrial loan rate. The latter rate is available from http://www.federalreserve.gov/releases/e2/ spanning the period 1986Q1 onwards. This is extended backwards using the growth rate of the prime rate.

Further details on the construction of this series is available in Gambetti and Musso (2017).

- Macroeconomic and financial data: This data is obtained from FRED. The FRED codes are as follows: (1) Real GDP GDPC96, (2) CPI: CPIAUCSL, (3) 3-Month Treasury Bill Rate: TB3MS, (4) Real Private Investment : GDPIC96, (5) Real consumption expenditure (PCECC96), (6) Chicago Fed National Financial Conditions Index, (7) The Uncertainty index is taken from Jurado et al. (2015).

- Instruments for the proxy SVAR: (1) The excess bond premium (EBP) is taken from Gilchrist and Zakrajsek (2012) (data periods 1973Q1 to 2012Q4), (2) the measure of bank lending shocks (BCDZ) is defined in Bassett et al. (2014) (data periods 1992Q1 to 2010Q4), (3) innovations to the financial conditions index (JQ) is calculated by Jermann and Quadrini (2012) (data periods 1984Q2 to 2010Q2) and the risk shock (CMR) is taken from the DSGE model of Christiano et al. (2014) (1981Q1 to 2010Q1). In addition, we calculate a textual measure of credit supply shocks in the spirit of similar measures developed to estimate changes in uncertainty (see Baker et al. (2017)) (data periods 1980Q1 to 2012Q4).

\section{References}

Alessandri, P. and H. Mumtaz (2014, October). Financial Regimes and Uncertainty Shocks. Working Papers 729, Queen Mary University of London, School of Economics and Finance.

Arias, J. E., J. F. Rubio-Ramirez, and D. F. Waggoner (2014, April). Inference Based on SVARs Identified with Sign and Zero Restrictions: Theory and Applications. International Finance Discussion Papers 1100, Board of Governors of the Federal Reserve System (U.S.).

Baker, S. R., N. Bloom, and S. J. Davis (2017). Measuring economic policy uncertainty. The Quarterly Journal of Economics Forthcoming. 
Barnett, A. and R. Thomas (2014, 09). Has Weak Lending and Activity in the UK been Driven by Credit Supply Shocks? Manchester School 82(S1), 60-89.

Bassett, W. F., M. B. Chosak, J. C. Driscoll, and E. Zakrajsek (2014). Changes in bank lending standards and the macroeconomy. Journal of Monetary Economics 62(C), 23-40.

Baumeister, C. and J. D. Hamilton (2015, 09). Sign Restrictions, Structural Vector Autoregressions, and Useful Prior Information. Econometrica 83(5), 1963-1999.

Bijsterbosch, M. and M. Falagiarda (2014, August). Credit supply dynamics and economic activity in euro area countries: a time-varying parameter VAR analysis. Working Paper Series 1714, European Central Bank.

Bloom, N. (2009, 05). The impact of uncertainty shocks. Econometrica 77(3), 623-685.

Calvo, G. A. (1983, September). Staggered prices in a utility-maximizing framework. Journal of Monetary Economics 12(3), 383-398.

Christiano, L., R. Motto, and M. Rostagno (2014). Risk shocks. American Economic Review $104(1), 27-65$.

Curdia, V. and M. Woodford (2010, 09). Credit Spreads and Monetary Policy. Journal of Money, Credit and Banking 42(s1), 3-35.

Del Negro, M., S. Eusepi, M. Giannoni, A. Sbordone, A. Tambalotti, M. Cocci, R. Hasegawa, and M. H. Linder (2013, December). The FRBNY DSGE model. Staff Reports 647, Federal Reserve Bank of New York.

Del Negro, M., M. P. Giannoni, and F. Schorfheide (2015). Inflation in the great recession and new keynesian models. American Economic Journal: Macroeconomics 7(1), 168-96.

Eickmeier, S. and T. Ng (2015). How do us credit supply shocks propagate internationally? a gvar approach. European Economic Review 74, 128 - 145.

Furlanetto, F., F. Ravazzolo, and S. Sarferaz (2014, July). Identification of financial factors in economic fluctuations. Working Paper 2014/09, Norges Bank.

Gale, D. and M. Hellwig (1985). Incentive-compatible debt contracts: The one-period problem. The Review of Economic Studies 52(4), pp. 647-663.

Gambetti, L. and A. Musso (2017). Loan supply shocks and the business cycle. Journal of Applied Econometrics. Forthcoming.

Gerali, A., S. Neri, L. Sessa, and F. M. Signoretti (2010, 09). Credit and banking in a dsge model of the euro area. Journal of Money, Credit and Banking 42(s1), 107-141. 
Gertler, M. and S. Gilchrist (1994, May). Monetary policy, business cycles, and the behavior of small manufacturing firms. The Quarterly Journal of Economics 109(2), 309-40.

Gertler, M. and P. Karadi (2011, January). A model of unconventional monetary policy. Journal of Monetary Economics 58(1), 17-34.

Giacomini, R. and T. Kitagawa (2014, November). Inference about Non-Identi?ed SVARs. CeMMAP working papers CWP45/14, Centre for Microdata Methods and Practice, Institute for Fiscal Studies.

Gilchrist, S. and E. Zakrajsek (2012, June). Credit spreads and business cycle fluctuations. American Economic Review 102(4), 1692-1720.

Jermann, U. and V. Quadrini (2012, February). Macroeconomic effects of financial shocks. American Economic Review 102(1), 238-71.

Jurado, K., S. C. Ludvigson, and S. Ng (2015, March). Measuring Uncertainty. American Economic Review 105(3), 1177-1216.

Kashyap, A. K., J. C. Stein, and D. W. Wilcox (1993, March). Monetary policy and credit conditions: Evidence from the composition of external finance. American Economic Review 83(1), 78-98.

Kilian, L. and D. P. Murphy (2012, October). Why agnostic sign restrictions are not enough: Understanding the dynamics of oil market var models. Journal of the European Economic Association 10(5), 1166-1188.

Lanne, M., H. Lutkepohl, and K. Maciejowska (2010, February). Structural vector autoregressions with Markov switching. Journal of Economic Dynamics and Control 34(2), $121-131$.

Liu, Z., P. Wang, and T. Zha (2013, 05). Land-price dynamics and macroeconomic fluctuations. Econometrica $81(3), 1147-1184$.

Lown, C. and D. P. Morgan (2006, September). The credit cycle and the business cycle: New findings using the loan officer opinion survey. Journal of Money, Credit and Banking 38(6), $1575-1597$.

Mertens, K. and M. O. Ravn (2013, June). The Dynamic Effects of Personal and Corporate Income Tax Changes in the United States. American Economic Review 103(4), 1212-47.

Mertens, K. and M. O. Ravn (2014). A reconciliation of SVAR and narrative estimates of tax multipliers. Journal of Monetary Economics 68(S), S1-S19.

Peersman, G. (2011, December). Bank lending shocks and the euro area business cycle. Working Papers of Faculty of Economics and Business Administration, Ghent University, Belgium 11/766, Ghent University, Faculty of Economics and Business Administration. 
Pinter, G., K. Theodoridis, and T. Yates (2013). Risk news shokc and the business cycle. mimeo.

Rigobon, R. (2003). Identification through heteroskedasticity. The Review of Economics and Statistics 85(4), 777-792.

Romer, C. D. and D. H. Romer (2004, September). A new measure of monetary shocks: Derivation and implications. American Economic Review 94(4), 1055-1084.

Rubio-Ramirez, J. F., D. F. Waggoner, and T. Zha (2010). Structural vector autoregressions: Theory of identification and algorithms for inference. Review of Economic Studies ry(2), 665-696.

Smets, F. and R. Wouters (2007). Shocks and frictions in US business cycles: a Bayesian DSGE approach. American Economic Review 97, 586-606.

Stock, J. H. and M. W. Watson (2008). WhatŠs new in econometrics- time series. Lecture 7, National Bureau of Economic Research, Inc.

Stock, J. H. and M. W. Watson (2012, May). Disentangling the Channels of the 2007-2009 Recession. NBER Working Papers 18094, National Bureau of Economic Research, Inc.

Uhlig, H. (2004, 04/05). Do Technology Shocks Lead to a Fall in Total Hours Worked? Journal of the European Economic Association 2(2-3), 361-371. 